\title{
UNIVERSITY OF CALIFORNIA
}

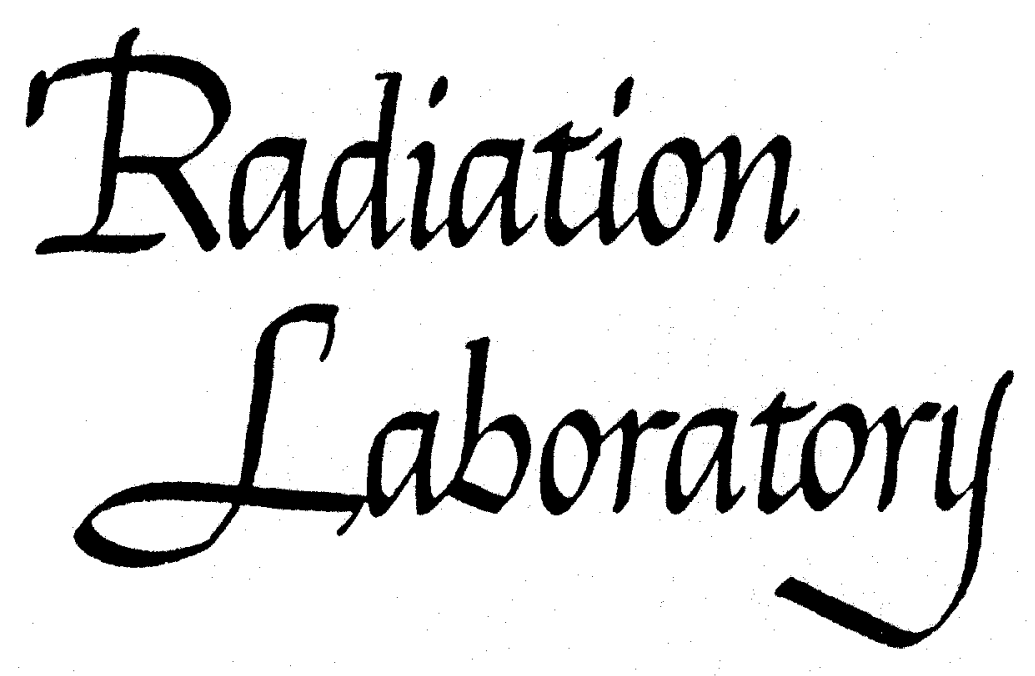

TWO.WEEK LOAN COPY

This is a Library Circulating Copy which may be borrowed for two weeks.

For a personal retention copy, call

Tech. Info. Division, Ext. 5545

BERKELEY, CALIFORNIA 
UCRL -8420

\author{
UNIVERSITY OF CALIFORNIA \\ Radiation Laboratory \\ Berkeley, California \\ Contract No. N -7405 -eng -48
}

RECENT DEVELOPMENTS IN THE FIELD OF THE TRANSPLUTONIUM ELFNENTS

Glenn T. Seaborg

Evening Speech at United Nations Second International Conference on the Peaceful Uses of Atomic Energy, Geneva, Switzerland

September 10, 1958

Printed for the U.S. Atomic Energy Commission 
This report was prepared as an account of Government sponsored work. Neither the United States, nor the Commission, nor any person acting on behalf of the Commission:

A. Makes any warranty or representation, express or implied, with respect to the accuracy, completeness, or usefulness of the information contained in this report, or that the use of any information, apparatus, method, or process disclosed in this report may not infringe privately owned rights; or

B. Assumes any liabilities with respect to the use of, or for damages resulting from the use of any information, apparatus, method, or process disclosed in this report.

As used in the above, "person acting on behalf of the Commission" includes any employee or contractor of the Commission to the extent that such employee or contractor prepares, handles or distributes, or provides access to, any information pursuant to his employment or contract with the Commission. 
RECENT DEVELOPMENTS IN THE FTELD OF THE TRANSPLUTONIUM ELEMENTS

Glenn T. Seaborg

Radiation Laboratory and Department of Chemistry

University of California, Berkeley, California

I plan to tell you tonight about some of the most interesting aspects of recent research on the synthetic transplutonium elements. The amount of recent information on these elements is obviously too much to cover completely in the time that has been placed at my disposal. Therefore, in planning my talk, I have attempted to choose those toples which have the broadest implications for the whole transuranium field of research. Although much important and interesting research is, of course, being done in many laboratories, I have chosen examples mainly from the work in our own laboratory, the Radiation Laboratory at the University of California in Berkeley. I shall cover this information about the known transplutonium elements, listed in Slide No. 1 , by discussing them in order of increasing atomic number, and I shall conclude with some thoughts concerning the prospects for elements with higher atomic numbers than any that have been produced and identified up to the present time. For purposes of orientation, slide No. 2 shows the position in the periodic table of the presently known and the future transuranium elements. The transplutonium elements through element 103, together with the five preceding elements, are members of the "heavy rare earth," or actinide transition series, which is analogous to the lighter rare earth, or lanthanide, transition series. The undiscovered "trans-103" elements will fit into the perlodic table as shown. I shall, of course, refer in my talk to the important unifying principle embodied in the periodic table.

\section{Americium and Curium}

Increasing amounts of the first two transplutonium elements, americium (atomic number 95) and curium (atomic number 96), are now becoming available for research in a number of laboratories even though the amounts are not nearly sufficient to meet the needs of the many impatient investigators. To date, most studies of americium and curium have been made using the isotopes $\mathrm{Am}^{241}$ and $\mathrm{cm}^{242}$ and have been hampered by the high alpha radioactivity of these two isotopes. Of great importance, therefore, is the fact that useful amounts of 
the less radioactive $\mathrm{Am}^{243}$ and $\mathrm{Cm}^{244}$ and higher mass curium isotopes are now being produced. Their availability will greatly facilitate chemical investigation of these elements.

of particular interest is the determination of the electronic structure of the ground state of curium by J. C. Hubbs and co-workers, working with W. A. Nierenberg, They found that curium has an electronic structure exactly analogous to that of gadolinium, as was predicted on the basis of its position at the midpoint of the actinide series. With the completion of this experiment the electronic structures of the ground states of all the elements in the first half of the actinide series of elements are now known. The electronic configurations of these elements and their homologues in the lanthanide series are shown in Slide No. 3. It should be pointed out that these actinide elements do not exhibit the pure Russell-Saunders (or I-S) type of coupling of their electrons as do the analogous lanthanfde elements but the $5 f$ and $6 \mathrm{~d}$ electrons of the actinides are separately in Russell-Saunders coupling and are weakly coupled to each other. Slide No. 4 shows the predicted, but as yet undetermined, electronic structures of the elements in the second half of the actinfde group together with the known structures of the homologous lanthanide elements.

The electronic configurations of curium and most of the preceding actinide elements have been determined through the study of the hyperfine structure of the free atoms by the atomic beam method. Slide No. 5 illustrates the basic elements of the method. A crucible is filled with the material under investigation and heated to $1000-3000^{\circ} \mathrm{C}$ to produce a beam of neutral atoms. This beam passes through a system of collimating and analyzing slits and three magnets, two of which, labelled $A$ and $B$, produce deflecting fields. This system is arranged so that normally no atoms can reach the detector. If, however, an appropriate transition between magnetic substates in the atoms is induced in the homogeneous field produced by magnet $c$, a portion of the beam can reach the detector. Thus one can study the hyperfine structure of free atoms, which is a function of both electronic and nuclear structure. The hyperfine structure interaction involves predominantly the interaction of the nuclear magnetic dipole moment with the magnetic field at the nucleus arising from valence or unpaired electrons. The principal electronic information derived is the electronic angular momentum and Lande $g$-factor of all electronic states within 
several thousand $\mathrm{cm}^{-1}$ of the ground state. This information, in combination with chemical, paramagnetic, optical and crystal structure data is, in general, sufficient to allow a unique assignment; of ground state electronic configurations. The atomic beam technique is adaptable to the use of trace quantities of radioactive materials and thus offers promise for the determination of the electronic structures of all the transuranium elements.

\section{Berkelium anä Californium}

Very recently S. G. Thompson and B. B. Cunningham succeeded in isolating berkelium (atomic number 97) and californium (atomic number 98) in macroscopic or weighable amounts for the first time. In April of this year these investigators isolated 0.4 microgram of berkelium (as $\mathrm{Bk}^{249}$ ) which had been formed as a result of the irradiation of about 8 grams of $\mathrm{Pu}^{239}$ and 1ts transmutation products with neutrons for approximately five years in the Materials Testing Reactor (MTR) at Arco, Idaho. The first macroscopic quantity of californium isolated was obtained in July of this year and consisted of 0.06 microgram of a mixture of the isotopes $\mathrm{Cf}^{249}, \mathrm{Cf}^{250}, \mathrm{Cf}^{251}$, and $\mathrm{Cf}^{252}$ which had been prepared by the same method as the berkelium.

W1th these materlals, Thompson and Cunningham measured the magnetic susceptibllities of berkellum and californium over the temperature range 77 to $298^{\circ} \mathrm{K}$. The data obtained for californium (and gadolinium for purpose of comparison) are shown in slide No. 6 . The results obtained in both investigations agree very well with those expected for berkelium and californium as may be seen from slide No. 7. In this slide are plotted the magnetic moments, determined by experiment and by theory, for a number of actinide elements. The data are consistent only with the fllling of the " 5 " electronic shell in the actinide elements. A plot of the magnetic moments of the lanthanide elements falls almost exactly on the theoretical curve shown.

The absorption spectra of the lons $\mathrm{Bk}^{+3}$ and $\mathrm{Cf}^{+3}$ in aqueous solution have been studied also. Visual observation failed to reveal absorption for either ion in the region from about 4600 to $7400 \mathrm{~A}$, but a photographic method has shown that broad and quite faint absorption bands occur in californium around 7800 and $8300 \mathrm{~A}$. The absorption spectrum of $\mathrm{Cf}^{+3}$ (and dysprosium for purpose of comparison) in 
dilute hydrochloric acid solution is represented in Slide No. 8. Rough estimates indicate that the absorption intensities are much weaker than those observed in the lighter actinides, and, in fact, have intensities comparable to those found. typically in lanthanide ions. This indicates that as the $5 f$ electron shell becomes more deeply embedded in the second half of the actinide series the elements begin to resemble the lanthanide elements even more.

A reduction in absorption intensity with increased lon charge has been noticed in the lighter actinides by Jorgensen. "This would appear to be related to the effect mentioned, since in each case the diminished intensity is associated with an increase in effective nuclear charge.

\section{EInsteinium and Fermium}

Although it is not of very recent occurrence it seems worthwhile to review the discoveries of the next two transplutonium elements, einsteinium (atomic number 99) and fermium (atomic number 100) in view of the possible ut1lity of their method of production for the future synthesis of new isotopes and elements. The discoveries of these two elements were unexpected by-products of the first test thermonuclear explosion to be produced. Finsteinium and fermium were discovered only because routine chemical identifications of fallout substances were made in connection with such tests in order to establish the properties of the explosion.

Heavy isotopes such as the previously unknown $\mathrm{Pu}^{244}$ and $\mathrm{Pu}^{246}$ were detected In the initial investigation of the debris and their presence suggested that very heavy uranium isotopes had been formed in the explosion by the irradiation of the uranium in the device by the extremely high neutron flux that existed for microseconds. The neutrons were captured within this very small fraction of a second and since beta decay will not, in general, proceed with a half life shorter than about 0.1 second, there was no opportunity for beta decay to occur during the synthesis. The subsequent beta decay of the heavy uranium isotopes led to the nuclides found in the explosion debris. In Slide No. 9 we can see the reaction paths by which these heavy elements were formed. Thus, for example, the production of $\mathrm{Fm}^{255}$ was via the synthesis of $\mathrm{U}^{255}$ by neutron capture in $U^{238}$ followed by a long chain of short-lived beta decays, $U^{255} \stackrel{\beta^{-}}{\longrightarrow}$ $\mathrm{Np}^{255} \stackrel{\mathrm{\beta}^{-}}{\longrightarrow} \mathrm{Pu}^{255} \stackrel{\mathrm{\beta}^{-}}{\longrightarrow} \cdots \mathrm{Fm}^{255}$, all of which occur after the neutron 
capture reactions are completed. Slice No. I0 shows the relative yields of heavy nuclides obtained in this first explosion.

Thermonuclear explosions offer a good method of producing new heavy isotopes of all the elements and possibly even new elements if the products can be recovered in better yield than has yet been possible. This method of synthesis of elements is similar to that which occurs in some stars. A particularly intriguing idea is the suggestion by the group of astrophysicists at the California Institute of Technology that a main source of energy for certain types of super-novae comes from the isotope $\mathrm{Cf}^{254}$.

Einsteinium is the only transuranium element capable of isolation, but not yet isolated, in macroscopic quantity (through its 280 -day isotope $\mathrm{E}^{254}$ ), and it seems likely that this will be accomplished within the next year or two, the material to be prepared through the neutron irradiation of elements of high atomic number for a prolonged period. Isotopes of transeinsteinium elements are expected to have half lives too short to permit their isolation in weighable amount.

\section{Mendelevium}

Two 1sotopes of mendelevium (element 101) are now known, both being prepared by helium-ion bombardments of einsteinium in the form of the isotope $\mathrm{E}^{253}$. It is not presently feasible to synthesize mendelevium, or any other transfermium element, by slow neutron irradiation of elements of high atomic number because some of the intermediate isotopes which must capture neutrons have half lives too short to allow their presence in appreclable concentration as required.

In the experiments that resulted in the first detection of a mendelevium isotope, a new technique was developed that was later applied in work leading to the discovery of element 102 and presumably will be used in the further discoveries of new elements. In view of this, I shall briefly discuss the discorery of mendelevium.

The synthesis of element 101 was planned and accomplished with a target consisting of only about $10^{9}$ atoms of einsteinium as $\mathrm{E}^{253}$ which had been prepared by the neutron irradiation of plutonium. Up to this time, no one had attempted 
the detection of transmutation products produced by the charged particle bombardment of invisible amounts of material and $10^{9}$ atoms is invisible by many orders of magnitude! Calculations indicated that on the basis of the estimated cross section for the reaction only one atom of element 101 per experiment could be expected. The approximate number of atams of element 101, N, expected in a bombardment was calculated as shown in slide No. $11 . N^{\prime}$ is the number of einsteinium atoms used as a target; $\sigma$, the cross section for the reaction which was predicted to be about $10^{-27}$ squere centimeters on the basis of the known value for previously observed similar reactions; $I$, the intensity of the helium ion beam which was about $10^{14}$ particles per second per square centimeter; and $t$, the predicted half life for the isotopes expected, which was of the order of $10^{4}$ seconds. Using these numbers and some arithmetic we can see that the preparation: of only about one atom per experiment could be expected! Element 101 was, however, successfully produced and identified in spite of the fact that the prediction of a yield of one atom per experiment was correct. Adding to the complexity of the experiment was the necessity for the separation of the one atom of element 101 from the target material and its chemical identification as a homologue of the rare earth thulium by the ionexchange method. The analogy between the ion-exchange behavior of corresponding actinide and lanthanide elements has been the key to the discovery of most of the transuranium elements. Their first known isotopes are available in exceedingly small amounts and may have very short existences; in addition, the transplutonium elements have a very close chemical resemblance. The ion exchange adsorption and elution technique, in contrast to most conventional chemical separation methods, has the necessary selectivity and rapidity in accomplishing the chemical identification of such elements. A preliminary separation of the atoms of element 101 from the einsteinium was accomplished by a new method, the recoil technique. Slide No. 12 illustrates this technique. The target was prepared by plating the einsteinium as a very thin layer onto a gold foil. The foil was bombarded by a beam of helium lons sent through the back of the foil so that the atoms of element 101, recoiling due to the momentum of the projectiles, could be caught on a second gold foil, the "catcher" foil. This second foil was dissolved and the chemical separations performed. The chemical identification was accomplished in an ion-exchange experiment involving the combined products 
from three successive bombardments in which a total of five spontaneous fission counts and hence five atoms was observed in the element 101 elution position. Slide No. 13 shows the elution data obtained. The activity of the $\mathrm{E}^{253}$ and $\mathrm{Cf}^{246}$, present as tracers for calibration purposes, is due to alpha particles. The first mendelevium isotope discovered has the mass number 256 and decays by electron capture with a half life of about a half hour to $\mathrm{Fm}^{256}$ which is responsible for the spontaneous fission decay. The fact that the radioactive decay involved the spontaneous fission process was a fortunate circumstance. This mode of decay has a high, almost 100 percent, detection efficiency and zero background.

Later confirmatory experiments using larger amounts of target $\mathrm{E}^{253}$ have led to the production of hundreds of atoms of mendelevium per experiment.

Slide No. 14 summarizes the steps in the discovery of mendelevium and was reproduced from an interesting review of the mendelevium experiment which was published in the Soviet journal "Priroda." In this slide (I) represents the helium Ion beam; (2), the target; (3), the "catcher foil; (4), the dissolving of the catcher foil; (5), the ion exchange column showing the relative order of elution of elements 99,100 , and 101; and (6) and (7), the instruments for detection of the spontaneous fission involved in the decay of the mendelevium.

Recently a second 1sotope of mendelevium, with the mass number 255, has been prepared and identified by a group at the University of California Radiation Laboratory. It was prepared by the helium fon bombardment of $\mathrm{E}^{253}$ and was separated in much the same way as the first isotope of mendelevium to be discovered. The new isotope has a half life of about a half hour and decays by electron capture.

\section{Element 102}

In 1957 a team of scientists from Argonne National Laboratory in the United States, the Atomic Energy Research Establishment in Harwe1l, England, and the Nobel Institute for Physics in Stockholm, Sweden, announced the discovery of an isotope of element 102 as a result of research performed at the Nobel Institute. The isotope was reportedly produced by bombarding $\mathrm{Cm}^{244}$ with cyclotron-produced $\mathrm{c}^{13(+4)}$ Ions and decayed by the emission of $8.5 \mathrm{Mev}$ alpha 
particles with a half life of about 10 minutes. The name nobelium was suggested by this group for the element. Unfortunately, repeated experiments at the University of Calffornia Radiation Laboratory have failed to conflrm this discovery.

In April of 1958, A. Ghiorso, T. Sikkeland, J. R. Walton, and myself identified the isotope $102^{254}$ as a product of the bombardment of $\mathrm{Cm}^{246}$ with $C^{12}$ ions accelerated in the new heavy ion linear accelerator (HILAC) at Berkeley. The discovery was made possible by the use of a radically new method in which two physical separations were performed: first, the element 102 isotope was separated from the target material, and second, the atoms of the daughter element were separated from the parent element 102.

Slide No. 15 shows a schematic drawing of the experimental arrangement; this is shown in more detail in slide No. 16. The target consisted of curium deposited on a thin nickel foil, and it was enclosed in a container filled with helium gas. The curium was bombarded with $\mathrm{C}^{12}$ ions and the transmuted atoms were knocked into the helium gas to absorb their recoil energy. It was found that with a sufficient electric field strength practically all of these positively charged atoms could be attracted to a moving, negatively charged metallic belt, the "conveyor" belt placed directly beneath the target. The belt was then passed under a foil, the "catcher" foll, which was charged negatively relative to the belt. Approximately half of the element 102 atoms undergoing radioactive decay by alpha-particle emission would cause their daughter atoms to recoil from the surface of the belt to the catcher foil. The catcher foil was cut transversely to the direction of the belt motion into five equal length sections after a time of bombardment suited to the half life of the daughter atom to be examined, and each section was analyzed simultaneously in counters. It was possible to make all the desired measurements for identifying the daughter $\mathrm{Fm}^{250}$ atoms deposited on the catcher foils and thus to determine the half life of the parent of the recoiling atoms. It, was found that $\mathrm{Fm}^{250}$ could be collected on the catcher folls in accordance with a parent half life of 3 seconds. Changing the belt speed was found to change the distribution of the $\mathrm{Fm}^{250}$ on the catcher foil in a manner conforming to a three second parent. 
The $\mathrm{Fm}^{250}$ on the catcher foll was dissolved and separated from the other actinide elements present by the femiliar ion exchange adsorption and elution method. It was identified by its elution in the well known element 100 position. Slide No. 17 shows the elution curve obtained in an experiment where nine atoms of $\mathrm{Fm}^{250}$ were observed.

The investigators at the University of California have not yet made their suggestion for a name for element 202 .

\section{Future Elements}

The preparation and detection of new transuranium elements seems possible. Investigation of the known transuranium elements, which possess a total of about seven dozen isotopes, has led to a systematization of the radioactive decay data in such a manner that the decay properties of undiscovered nuclides can, in general, be successfully predicted. The predominant mode of radioactive decay of the transuranium elements is by alpha particle emission, but decay by the spontaneous fission process becomes more and more important as the elements of highest atomic number are approached. In fact, for some isotopes this latter mode of decay begins to proceed at a rate comparable to decay by alphe particle emission by the time element 100 is reached. The regularities for both modes of decay have been found to be greatest for nuclei which contain an even number of neutrons and an even number of protons, thus making predictions of the properties for undiscovered isotopes of this type the most certain. For isotopes with an odd number of protons or an odd number of neutrons or an odd number of both protons and neutrons, the rate of decay by both alpha decay and by spontaneous fission is slower than for the even type. Slide No. 18 shows the predicted half lives (indicated by a broken line) of the longest lived isotopes for elements up to element 110. Unless unexpected islands of stability due to closed neutron or proton shells are found, the predictions based on the regularities in the decay properties suggest that it should be possible to produce and detect not more than about six elements beyond the heaviest now known.

By the time elements 104 and 105 are reached, we shall probably find that the longest-lived isotopes that can be prepared will exist barely long 
enough for the performance of traditional methods of chemical identification; this will undoubtedly be made on isotopes with an add numer nueleons. The present criteria for the discovery of a new element, chemical identification by traditional methods and separation from all previously known elements, will probably have to be changed at some point. Careful investigations of decay properties and reaction yields and mechanisms, together with the use of the recoil technique combined in some cases with the chemical identification of daughter isotopes, should provide means for the satisfactory identification of isotopes with very short half lives. Decay properties may have to be measured at the target area, on recoll product nuclei, during the bombardment. In some cases, it may be possible to make a satisfactory identification of new element isotopes by using simple and fast methods involving the migration of gaseous atoms or lons, volatility properties, reactions with surfaces, or gasflow reactions. It is likely that the identification of the first isotopes of all the new elements that will be discovered in the future will be accomplished by such methods, and the production of isotopes of these new elements with sufficiently long half lives to allow chemical identification by traditional methods will follow later if this is possible at all. Regardless of the method used, evidence for the discovery of a new element should include a reasonable establishment of the atomic number, and this requires more than the observation of predicted decay properties and yields. For example, the establishment of unique genetic relationship with a known lower element, such as was done for element 102, may be taken as the required additional information. We may finc. that it will eventually not be possible to satisfy these requirements when the preparation and detection of elements substantially farther up the atomic number scale is under investigation some years from now.

The chemical properties of the elements beyond element 103 can be estimated to the same extent that membership of any element in a certain group or column in the periodic table foretells its chemical properties. The position in the periodic table of undiscovered elements up to element 118 can be predicted as a consequence of having determined the point of filling of the $5 f$ electron shell which occurs at element 103, although many of these elements will never be synthesized. It is expected that the actinide series will be completed at element 103 and that elements 104, 105, 106, etc. will be fitted in under 
hafniom, tantalum, tungsten, etc., including the positions occupied by thorium, protactinium, and uranium in the pre-World War II periodic tables. (Slide No. 19.) The filling of the 6 d electron shell should be followed by the addition of electrons to the $7 \mathrm{p}$ shell, with the rare gas structure being attained at element 118.

It seems probable that the chemical identification of element 103 and of isotopes of element 102 with sufficiently long half lives will be made by the ion exchange method which provides the necessary selectivity and rapidity. Slide No. 20 shows the elution position predicted for these two elements together with data obtained in experiments with other actinide and homologous lanthanide elements. Element $102 \mathrm{might}$ be expected to have, in addition to a stajle III oxidation state, a somewhat unstable II state in aqueous solution. The lower oxidation state may prove to be important in the eventual chemical identification of longer-lived isotopes of element 102. If the stability of this II state is comparable to the stability of the II state of ytterbium, then a rapid separation of this element from the other actinide elements may be effected through electrolytic or amalgam reduction, using ytterbium as a carrier. It is expected that the metallic form of element 102 will have a low density and a high volatility relative to the preceding actinide elements. Element 104 should be exclusively tetrapositive in aqueous solution and should resemble its homologues hafnium and zirconium. Element 104 would be expected to have a soluble fluoride which will permit its separation from other actinide elements by precipitating the insoluble fluorides of the tripositive actinides, leaving element 104 in solution. Solvent extraction may also prove to be a rapid and effective method of separating element 104 from the heavier tripositive actinide elements.

Element 105 should resemble niobium and tantalum and in some respects protactinium, with the $\mathrm{V}$ oxidation state expected to be the most important. Although it is not a true chemical homologue of protactinium, element: 105 might resemble protactinium in its carrying and solvent extraction properties. The chemical properties of element 106 can be deduced from those of tungsten and molybdenum. Thus we might expect to find the III, IV, V, and VI oxidation states. Elements 107, 108, 109, 110, etc. would be expected to have chemical properties similar to those of rhenium, osmium, irldium, platinum, etc., 
respectively, although isotopes sufficiently long-lived to permit study of their chemical properties may not exist

I shall consider next the methols by which these undiscovered elements might be prepared. As mentioned previously, the method of multiple slow neutron capture as a result of intense neutron irradiation of elements of high atomic number over a long period of time has lj.ttle utility in the first synthesis of transfermium elements. The production of new transuranium isotopes and elements in thermonuclear explosions, under proper auspices, of course, offers good possibilities as I mentioned earlier. Synthesis by heavy ion bombardment offers promise for the production of elements of high atomic number. Isotopes of californium, einsteinium, and fermium have been produced by the bombardment of uranium with carbon, nitrogen, and oxygen ions, respectively, and element 102 was discovered as a product of the bombardment of curium with carbon ions. These heavy ions can be accelerated in cyclotrons of the conventional type, but linear accelerators which will be devoted to the acceleration of heavy ions to energies sufficient to transmute the heaviest nuclei are also coming into operation in several laboratories throughout the world. Slide No, 21 shows a line drawing of the heavy ion linear accelerator (HILAC) at the University of California Radiation Laboratory in Berkeley, and Slides 22, 23, and 24 show pictures of this machine. Even with the use of heavy ions the reaction yields are small due to the competition of the fission reaction. This competition is the more severe the higher the atomic number and the heavier the projectile; the heavier projectile requires more energy to surmount the potential barrier, and this gives more excitation energy to the nucleus which leads to more steps of competition with fission as successive neutrons are emitted.

The lack of availability of target materials of high atomic number presents a serious problem. Slide No. 25 shows the reaction paths for the preparation of transplutonium elements by slow neutron irradiation of $\mathrm{Pu}^{239}$, and Slide No. 26, an indication of the time required for the preparation of $\mathrm{Cm}^{248}, \mathrm{Cf}^{252}$, and $\mathrm{E}^{254}$ is given. It can be seen that starting with one kilogram of $\mathrm{Pu}^{239}$ it would take approximately five years to produce one milligram of $\mathrm{Cf}^{252}$ at a neutron flux of $3 \times 10^{14}$ neutrons per square centimeter fer second. In the United States we have a program under way for the production of milligram amounts of berkelium, californium and einsteinium, which, unless 
a higher flux reactor is built, will employ a neutron flux of $3 \times 10^{14}$ in the later stages. According to present plans we would obtain about one milligram of $\mathrm{CP}^{252}$ in about ten years' time. In order to prepere milligram amounts of berkelium, californium, and einsteinlum on a more reasonable time scale, new, expensive, high-flux reactors producing $10^{15}$ to $10^{16}$ neutrons per square centimeter per second are needed.

In conclusion, it appears that we can look forward to the addition of new elements to the periodic table as a continuing result of modern-day alchemy. The transuranium elements will thus continue to add much to our knowledge of atomic and nuclear structure. 
95........AMERICIUM.............Am 96........CURIUM ..................... 97........BERKELIUM ..............Bk 98........CALIFORNIUM .........Cf 99.......EINSTEINIUM...........E 100......FERMIUM ................Fm IOI.......MENDELEVIUM......Mv $102 \ldots . . \quad-\quad \ldots . \ldots \ldots \ldots . .$.

Slide 1 


\begin{tabular}{|c|c|c|c|c|c|c|c|c|c|c|c|c|c|c|}
\hline$\left\{\begin{array}{l}1 \\
c\end{array}\right.$ & $\begin{array}{l}22 \\
\mathrm{Ti}\end{array}$ & $\begin{array}{l}23 \\
\mathrm{~V}\end{array}$ & $\begin{array}{l}24 \\
\mathrm{Cr}\end{array}$ & $\begin{array}{l}25 \\
M n\end{array}$ & $\begin{array}{l}26 \\
\mathrm{Fe}\end{array}$ & $\begin{array}{l}27 \\
\text { Co }\end{array}$ & $\begin{array}{l}28 \\
\mathrm{Ni}\end{array}$ & $\begin{array}{l}29 \\
\mathrm{Cu}\end{array}$ & $\begin{array}{l}30 \\
\mathrm{Zn}\end{array}$ & $\begin{array}{l}31 \\
\mathrm{Ga}\end{array}$ & $\begin{array}{l}32 \\
\mathrm{Ge}\end{array}$ & $\begin{array}{l}33 \\
\text { As }\end{array}$ & $\begin{array}{l}34 \\
\text { Se }\end{array}$ & \\
\hline 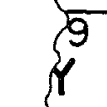 & $\begin{array}{l}40 \\
\mathrm{Zr}\end{array}$ & $\begin{array}{l}4 ! \\
\mathrm{Nb}\end{array}$ & $\begin{array}{l}42 \\
\text { Mo }\end{array}$ & $\begin{array}{l}43 \\
\text { TC }\end{array}$ & $\begin{array}{l}44 \\
\mathrm{Ru}\end{array}$ & $\begin{array}{l}45 \\
\mathrm{Rh}\end{array}$ & $\begin{array}{l}46 \\
\mathrm{Pd}\end{array}$ & $\begin{array}{l}47 \\
\mathrm{Ag}\end{array}$ & $\begin{array}{l}48 \\
\mathrm{Cd}\end{array}$ & $\begin{array}{l}49 \\
\text { In }\end{array}$ & $\begin{array}{l}50 \\
\text { Sn }\end{array}$ & $\begin{array}{l}51 \\
S b\end{array}$ & $\begin{array}{l}52 \\
\mathrm{Te}\end{array}$ & 5 \\
\hline & $\begin{array}{l}72 \\
\mathrm{Hf}\end{array}$ & $\begin{array}{l}73 \\
\mathrm{Ta}\end{array}$ & $\begin{array}{l}74 \\
W\end{array}$ & $\begin{array}{l}75 \\
\mathrm{Re}\end{array}$ & $\begin{array}{l}76 \\
\text { Os }\end{array}$ & $\begin{array}{l}77 \\
\mathrm{Ir}\end{array}$ & $\begin{array}{l}78 \\
\mathrm{Pt}\end{array}$ & $\begin{array}{l}79 \\
\mathrm{Au}\end{array}$ & $\begin{array}{l}80 \\
\mathrm{Hg}\end{array}$ & $\begin{array}{l}81 \\
\mathrm{TI}\end{array}$ & $\begin{array}{l}82 \\
\mathrm{~Pb}\end{array}$ & $\begin{array}{l}83 \\
\mathrm{Bi}\end{array}$ & $\begin{array}{l}44 \\
\text { Po }\end{array}$ & $\vec{A}$ \\
\hline & $(104)$ & $(105)$ & $(106)$ & $(107)$ & $(108)$ & $(109)$ & (IIO) & & & & & & & \\
\hline $\begin{array}{l}58 \\
\mathrm{Ce}\end{array}$ & $\begin{array}{l}59 \\
\mathrm{Pr}\end{array}$ & $\begin{array}{l}60 \\
\mathrm{Nd}\end{array}$ & $\begin{array}{l}61 \\
\mathrm{Pm}\end{array}$ & $\begin{array}{l}62 \\
\mathrm{Sm}\end{array}$ & $\begin{array}{l}63 \\
\text { Eu }\end{array}$ & $\begin{array}{l}64 \\
\text { Gd }\end{array}$ & $\begin{array}{l}65 \\
T b\end{array}$ & $\begin{array}{l}66 \\
\text { Dy }\end{array}$ & $\begin{array}{l}67 \\
\text { Ho }\end{array}$ & $\begin{array}{l}68 \\
\text { Er }\end{array}$ & $\begin{array}{l}69 \\
\mathrm{Tm}\end{array}$ & $\begin{array}{l}70 \\
Y b\end{array}$ & $\begin{array}{l}71 \\
\mathrm{Lu}\end{array}$ & \\
\hline $\begin{array}{l}90 \\
\text { Th }\end{array}$ & $\begin{array}{l}91 \\
\mathrm{~Pa}\end{array}$ & $\mathrm{U}^{92}$ & $\begin{array}{l}93 \\
\mathrm{~Np}\end{array}$ & $\begin{array}{l}94 \\
\mathrm{Pu}\end{array}$ & $\begin{array}{l}95 \\
\text { Am }\end{array}$ & $\begin{array}{l}96 \\
\mathrm{Cm}\end{array}$ & $\begin{array}{c}97 \\
B k\end{array}$ & $\begin{array}{l}98 \\
\text { Cf }\end{array}$ & $\begin{array}{l}99 \\
\mathrm{E}\end{array}$ & $\begin{array}{l}100 \\
\mathrm{Fm}\end{array}$ & $\begin{array}{l}101 \\
M V\end{array}$ & 102 & $(103)$ & \\
\hline
\end{tabular}




\section{KNOWN ELECTRONIC STRUCTURES}

89..ACTINIUM.........6 d7 $\mathrm{s}^{2} \quad$ 57..LANTHANUM....5 $\mathrm{d} 6 \mathrm{~s}^{2}$

90..THORIUM ..........6 $\mathrm{d}^{2} 7 \mathrm{~s}^{2} \quad$ 58..CERIUM......... $4 \mathrm{f}^{2} 6 \mathrm{~s}^{2}$

9I...PROTACTINIUM...5 $5 f^{2} 6 \mathrm{~d} 7 \mathrm{~s}^{2} \quad$ 59..PRASEODYMIUM. $.4 f^{3} 6 \mathrm{~s}^{2}$

$92 .$. URANIUM ..........5 $5 f^{3} 6 \mathrm{~d} 7 \mathrm{~s}^{2} \quad 60$. NEODYMIUM .....4f $6 \mathrm{f}^{4} 6 \mathrm{~s}^{2}$

93..NEPTUNIUM........5 $6 f^{4} 6 \mathrm{~d} 7 \mathrm{~s}^{2} \quad 61 .$. PROME THIUM.... $4 \mathrm{f}^{5} 6 \mathrm{~s}^{2}$

94..PLUTONIUM ........5 $f^{6} 7 \mathrm{~s}^{2} \quad$ 62..SAMARIUM...... $4 f^{6} 6 \mathrm{~s}^{2}$

95..AMERICIUM.......5 $f^{7} 7 \mathrm{~s}^{2} \quad$ 63..EUROPIUM......4f $6 \mathrm{f}^{7}$

96 CURIUM ............5 $5 f^{7} 6 \mathrm{~d} 7 \mathrm{~s}^{2} \quad 64 .$. GADOLINIUM....4 $4 f^{7} 5 \mathrm{~d} 6 \mathrm{~s}^{2}$ 


\section{ELECTRONIC STRUCTURES PREDICTED KNOWN}

$97 .$. BERKELIUM.......5 $\mathrm{f}^{8} 6 \mathrm{~d} 7 \mathrm{~s}^{2}$ 65..TERBIUM.........4 $4 \mathrm{f}^{9} 6 \mathrm{~s}^{2}$ $58^{3} 7^{2}$

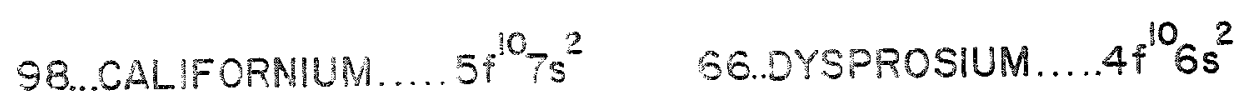
99..EINSTEINIUM......5 $5 t^{11} 7 s^{2}$ 67.HOLMIUM........4 $f^{11} 6 \mathrm{~s}^{2}$ 100.FERMUM.........5 $\mathrm{t}^{12} 7 \mathrm{~s}^{2}$ S8.ERBIUM .........4 $4 \mathrm{f}^{12} 6 \mathrm{~s}^{2}$ 101..MENDELEVIUM ...5: $55^{13} 7 s^{2}$ S9.THULIUM....... $4 f^{13} 6 s^{2}$ $102 \ldots .102 \ldots \ldots \ldots \ldots .5 f^{14} 7 s^{2} \quad$ TO.YTTERBIUM ....4 $4 f^{14} 6 \mathrm{~s}^{2}$

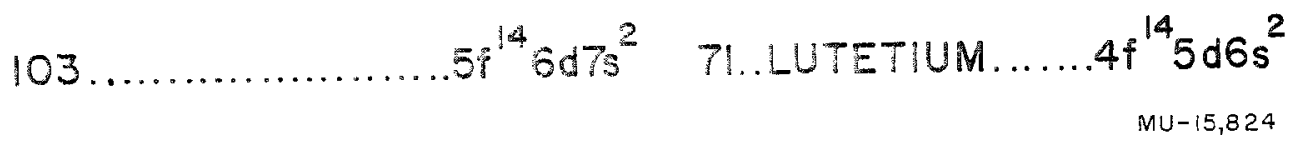


SCHEMATIC ARRANGEMENT OF AN ATOMIC BEAM APPARATUS

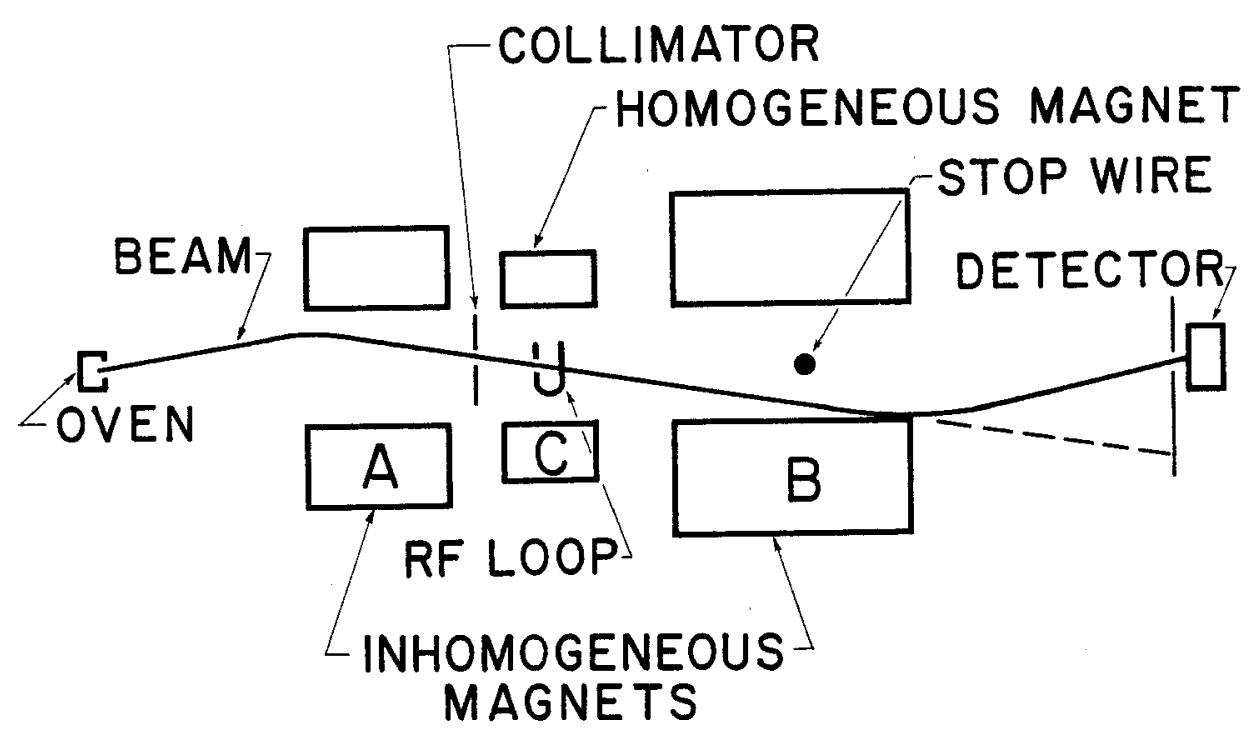

$M U-15,823$

Slide 5 


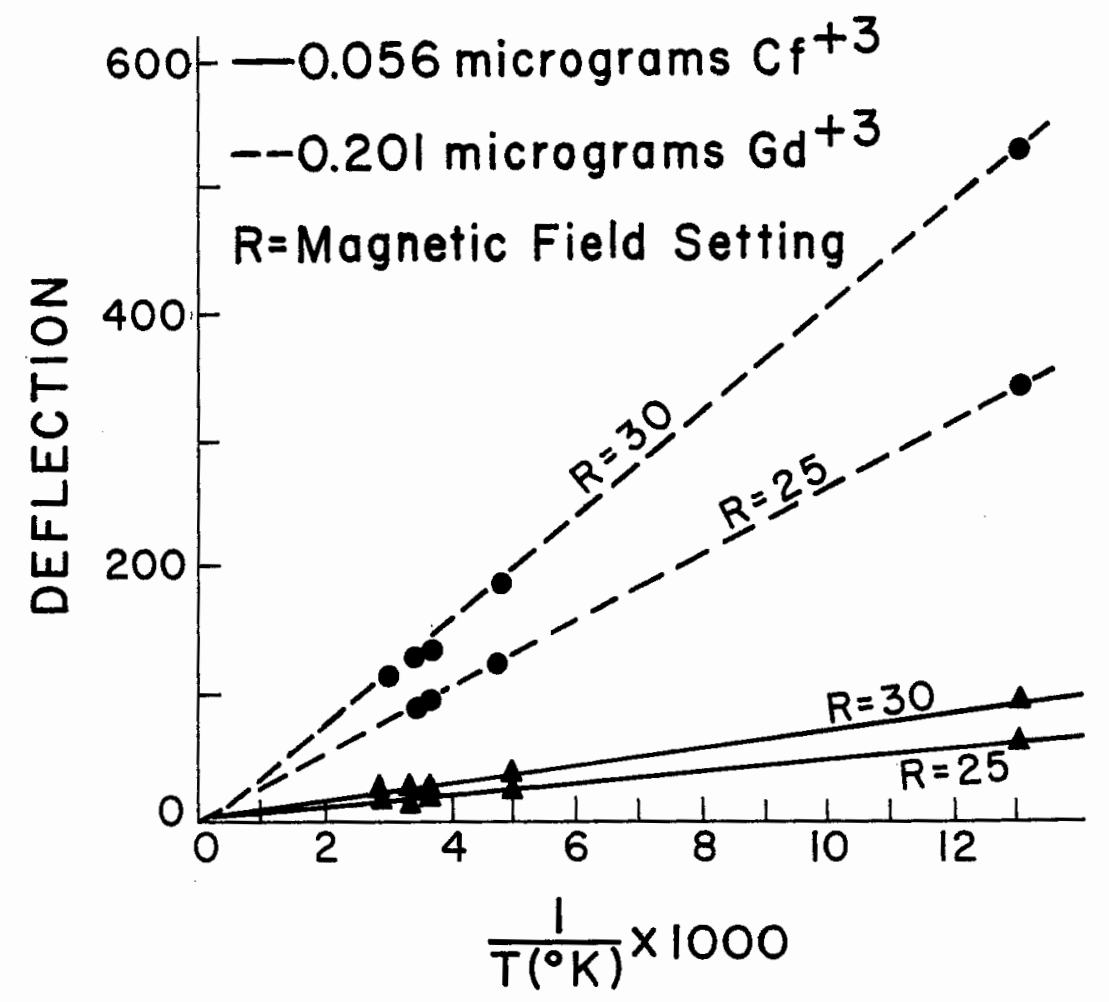

$M U-15,826$

Slide 6 


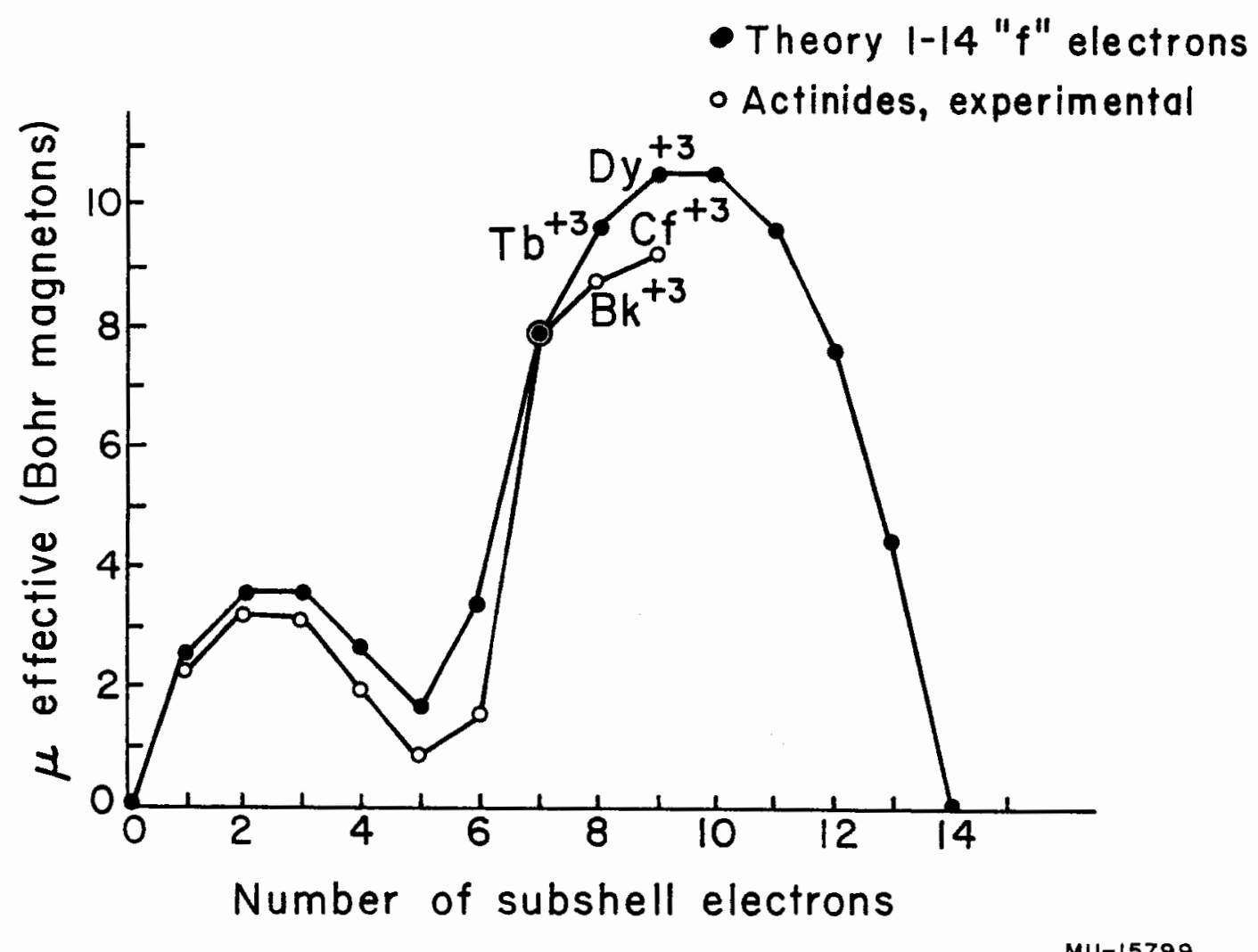

$M U-15799$

Slide 7 


\section{SOLUTION ABSORPTION SPECTRUM OF $\mathrm{Cf}^{+3}$}

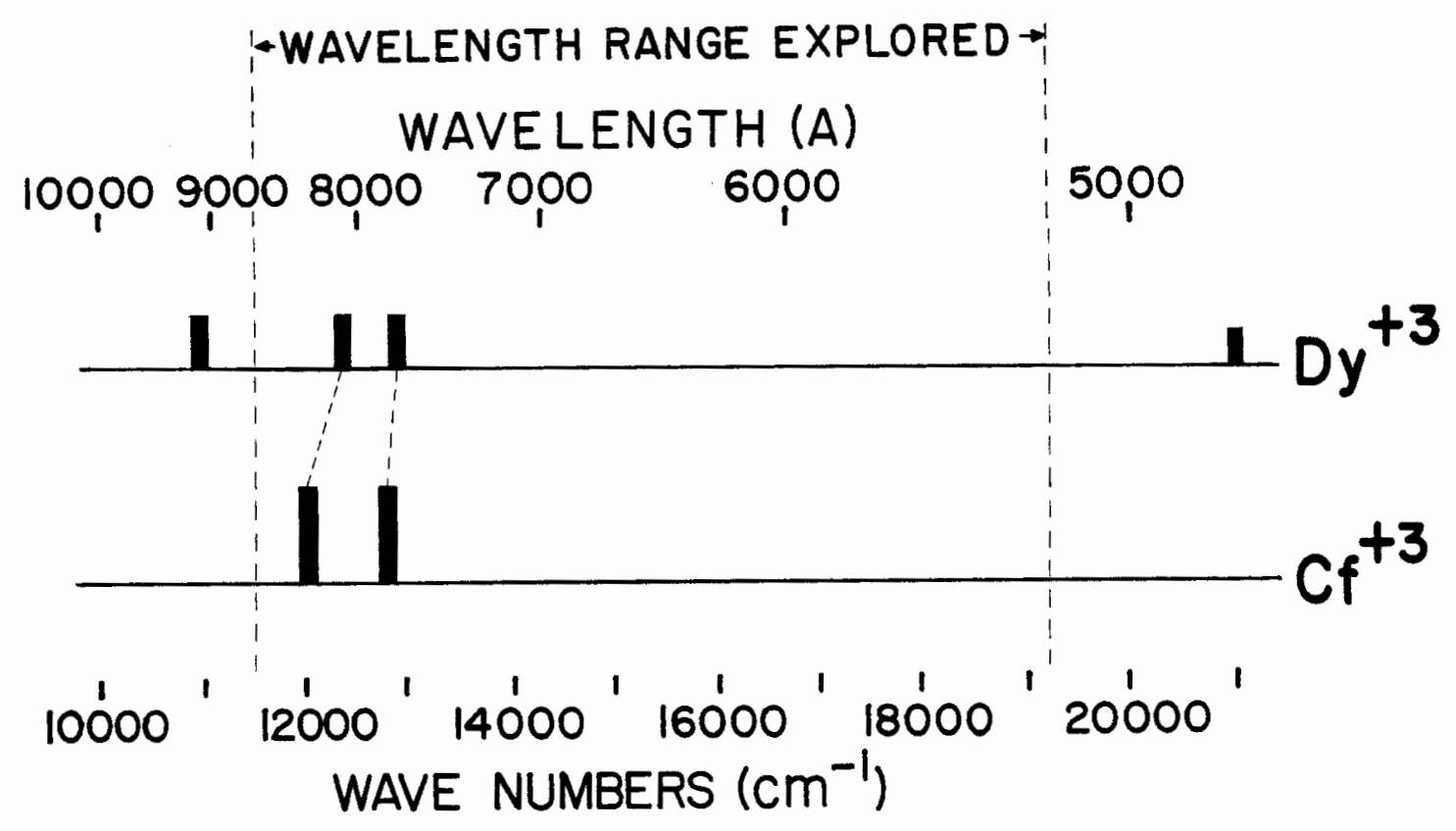

$M U-15,848$

Slide 8 


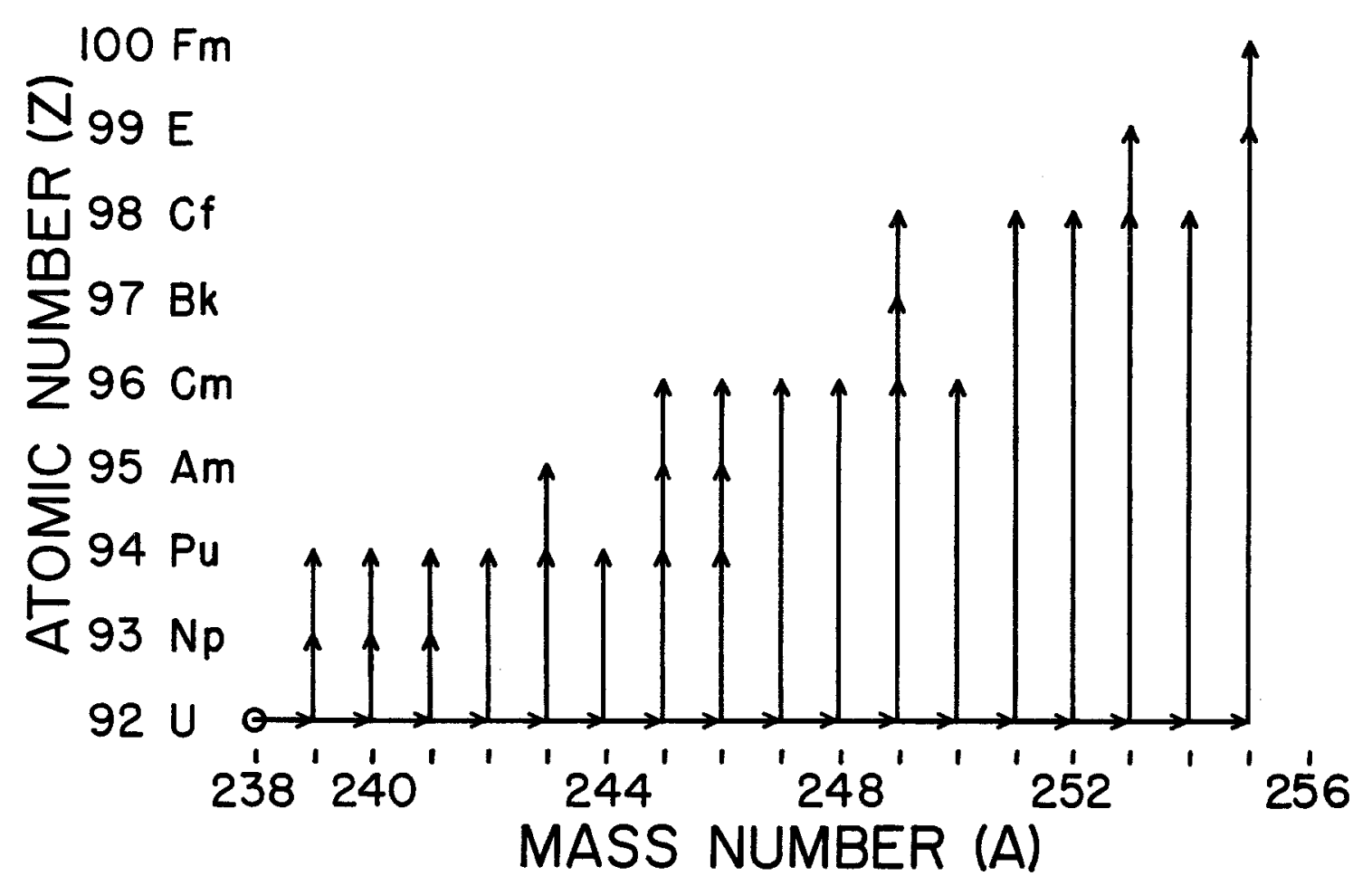

MU-13525 


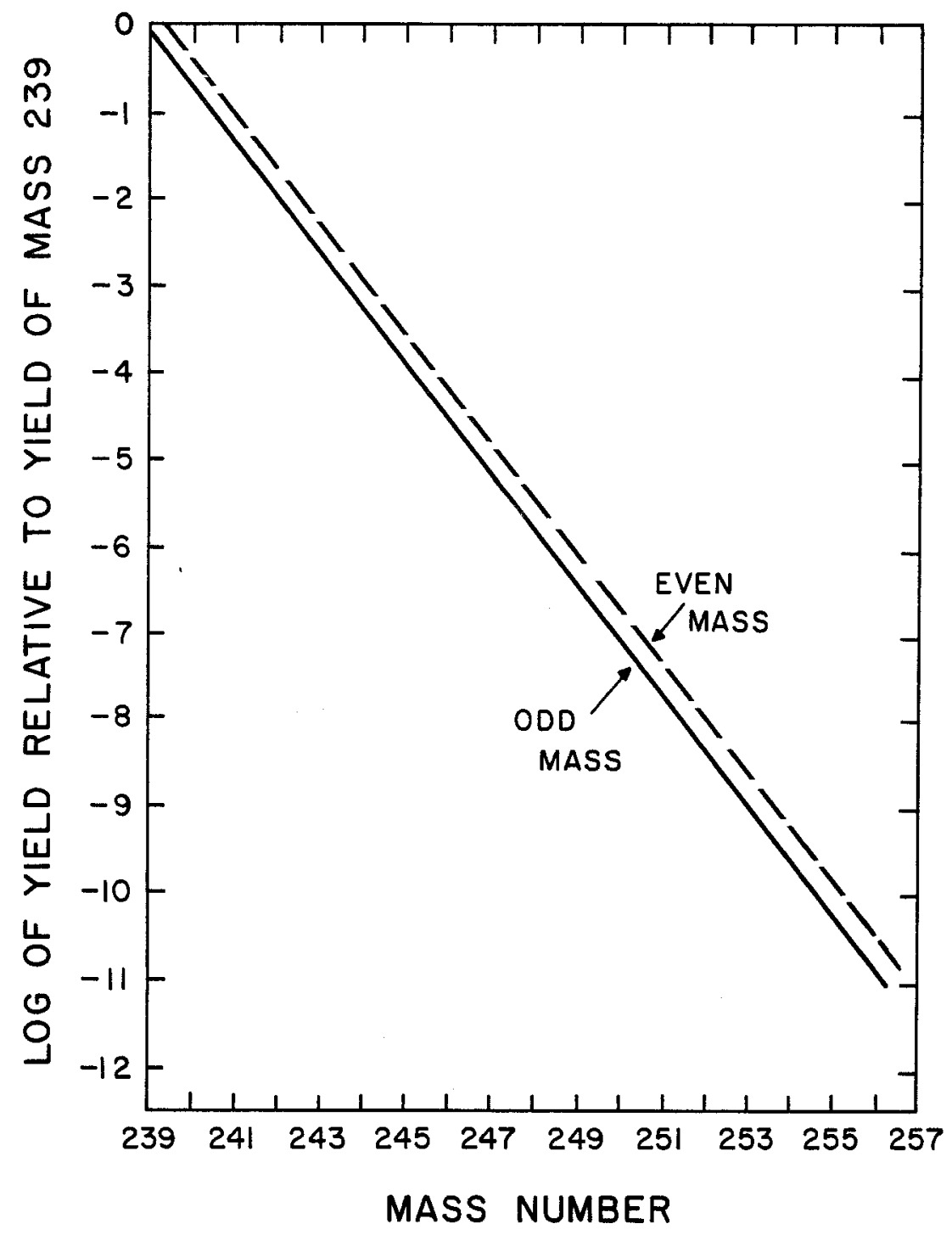

$M U-15786$

Slide 10 
$N \cong N^{\prime} \sigma I \dagger$

$\left(10^{9}\right)\left(10^{-27}\right)\left(10^{14}\right)\left(10^{4}\right) \cong$

One atom per experiment

$M U-15,819$

Slide 11 


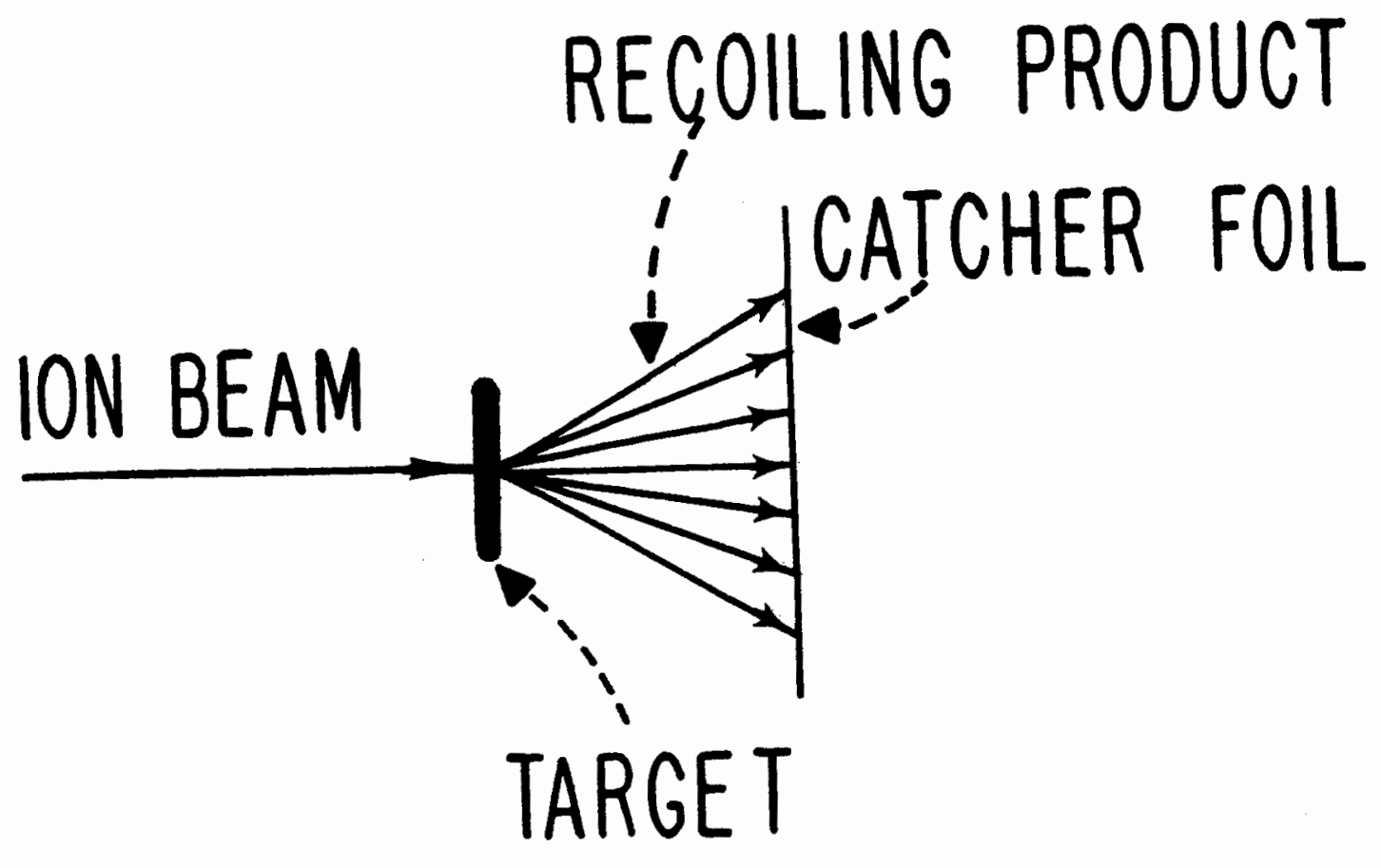

$M U-15758$ 


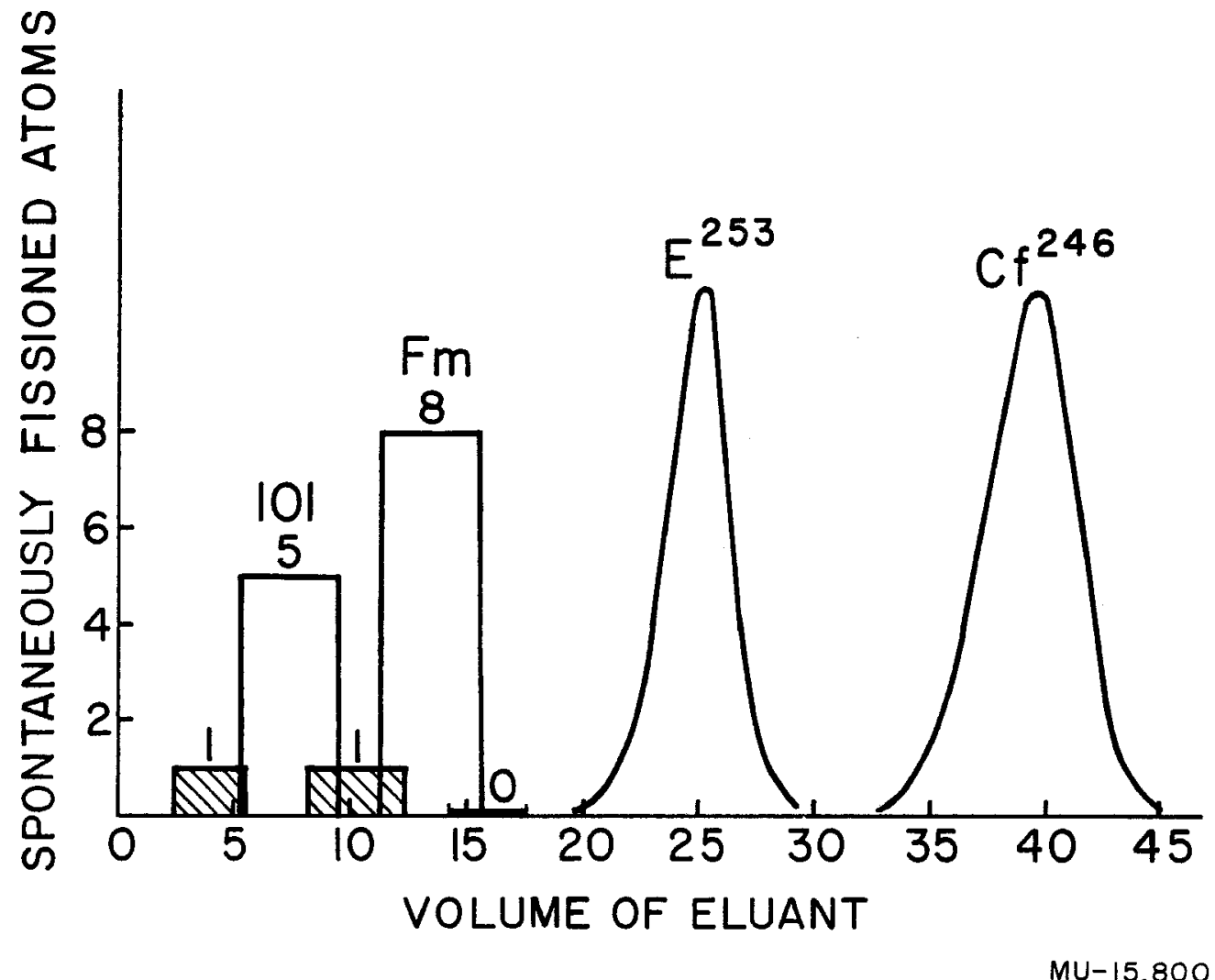

Slide 13 


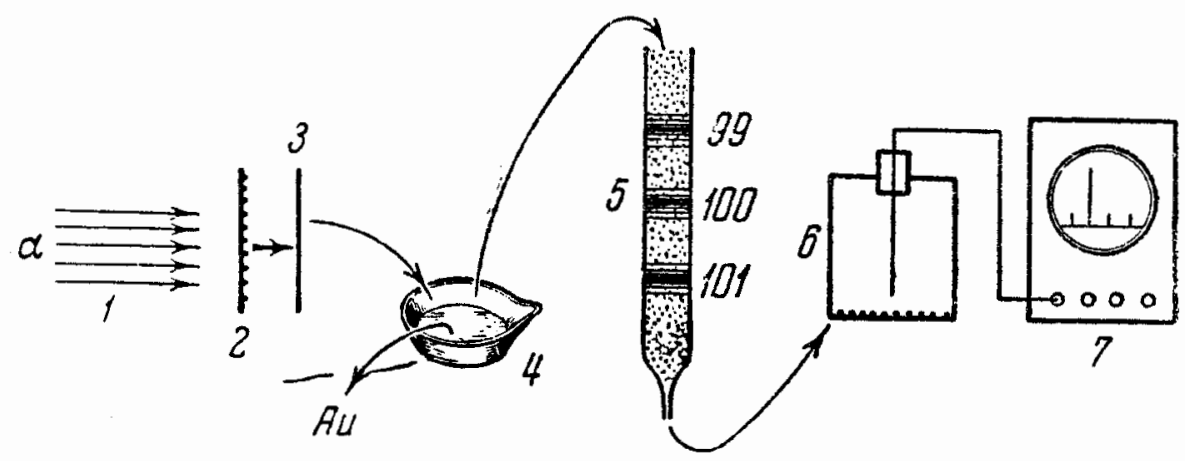

Slide 14 


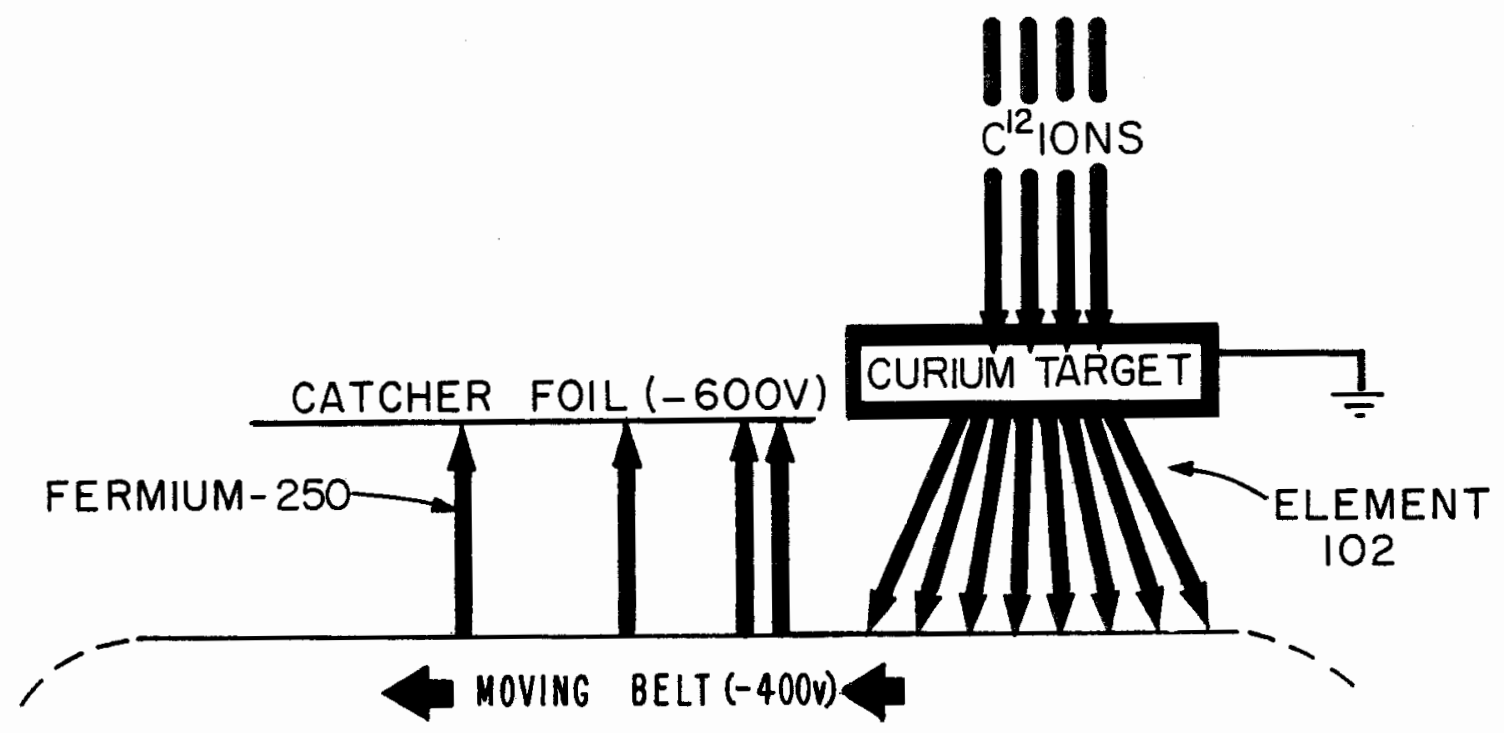

$M U-15,843$

Slide 15 


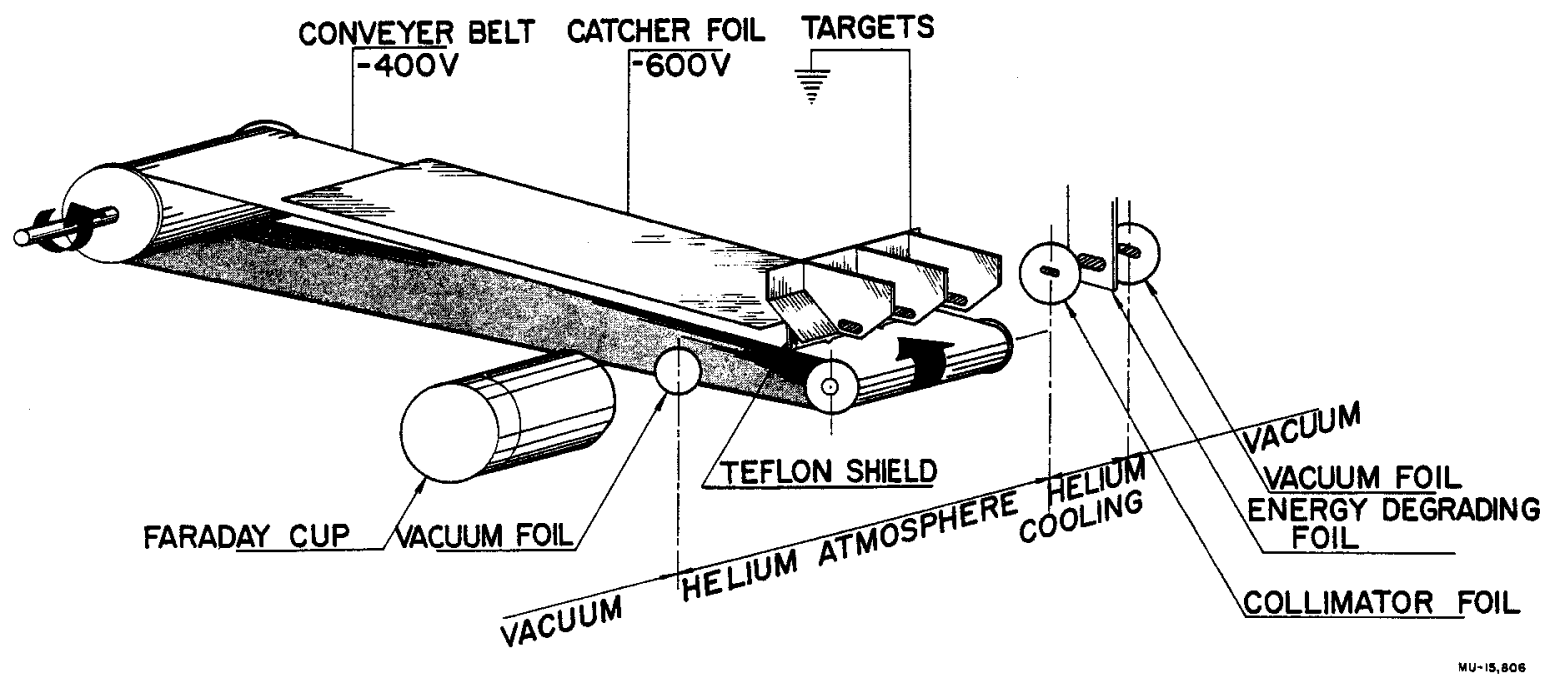

Slide 16 


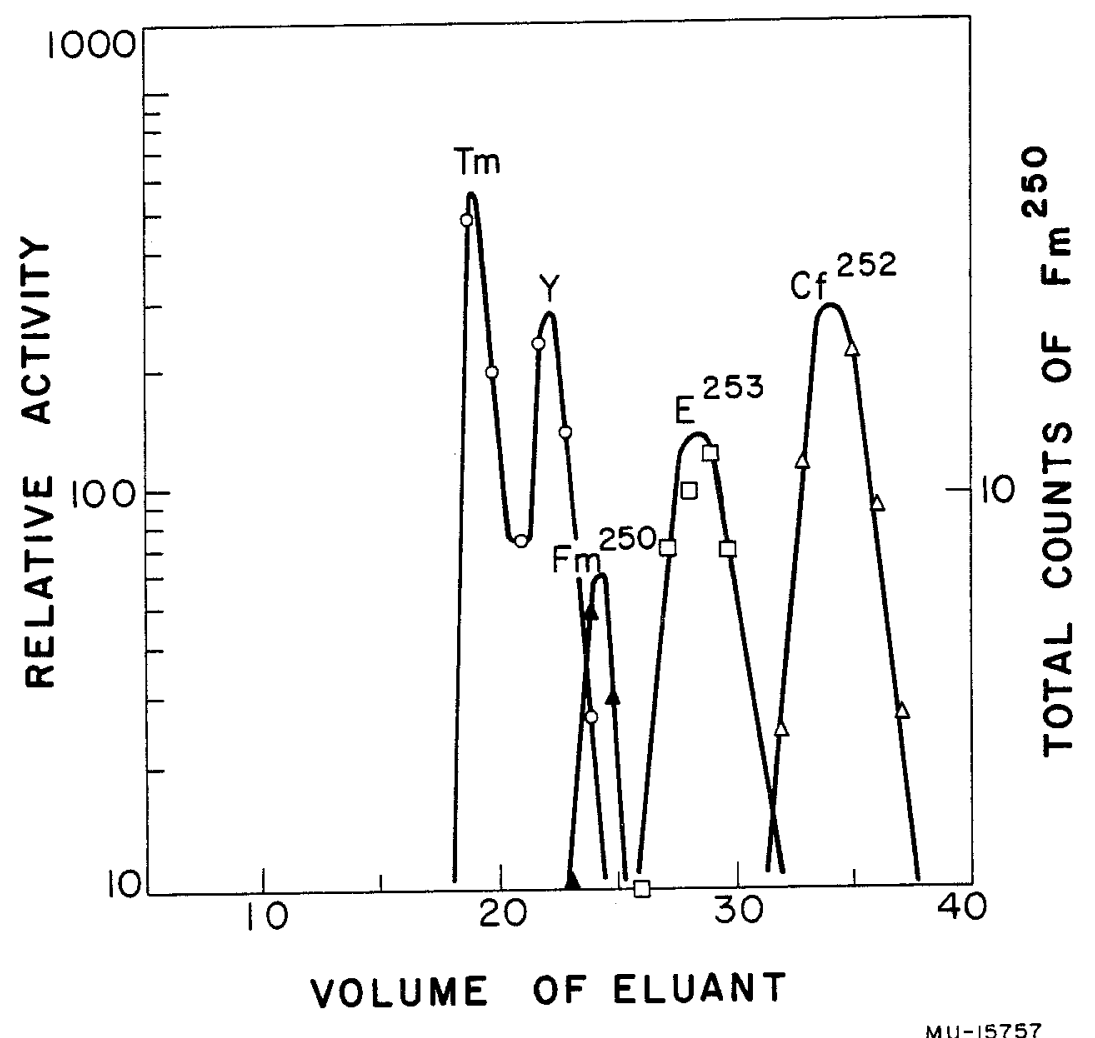

Slide 17 


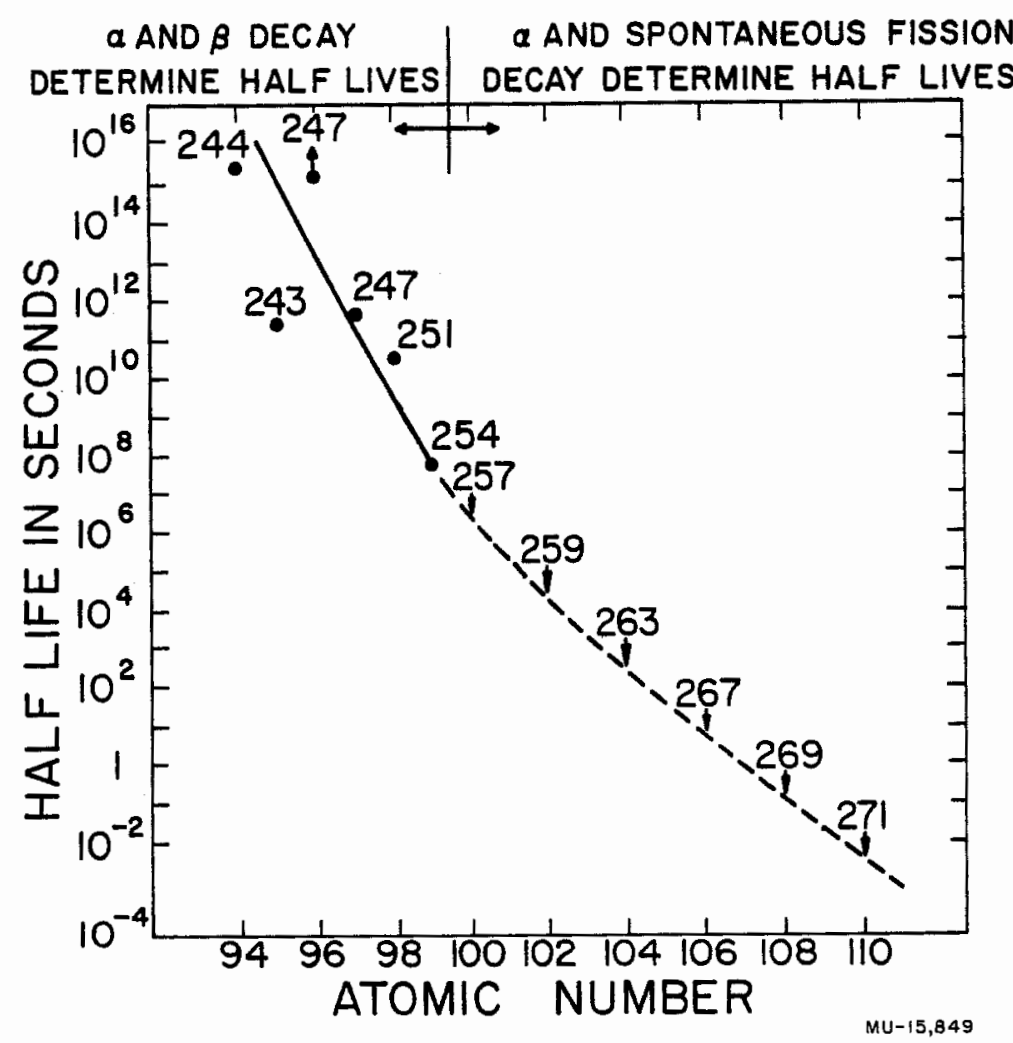

Slide 18 


\begin{tabular}{|c|c|c|c|c|c|c|c|c|c|c|c|c|c|c|}
\hline$\xi_{c}$ & $\begin{array}{l}22 \\
\mathrm{Ti}\end{array}$ & $\begin{array}{l}23 \\
V\end{array}$ & $\begin{array}{l}24 \\
\mathrm{Cr}\end{array}$ & $\begin{array}{l}25 \\
\mathrm{Mn}\end{array}$ & $\begin{array}{l}26 \\
\mathrm{Fe}\end{array}$ & $\begin{array}{l}27 \\
\text { Co }\end{array}$ & $\begin{array}{l}28 \\
\mathrm{Ni}\end{array}$ & $\begin{array}{l}29 \\
\mathrm{Cu}\end{array}$ & $\begin{array}{l}30 \\
\mathrm{Zn}\end{array}$ & $\begin{array}{l}31 \\
\mathrm{Ga}\end{array}$ & $\begin{array}{l}32 \\
\mathrm{Ge}\end{array}$ & $\begin{array}{l}33 \\
\text { As }\end{array}$ & $\begin{array}{l}34 \\
\mathrm{Se}\end{array}$ & 35 \\
\hline 9 & $\begin{array}{l}40 \\
\mathrm{Zr}\end{array}$ & $\begin{array}{l}4 ! \\
\mathrm{Nb}\end{array}$ & $\begin{array}{l}42 \\
\text { Mo }\end{array}$ & $\begin{array}{l}43 \\
\text { TC }\end{array}$ & $\begin{array}{l}44 \\
R u\end{array}$ & $\begin{array}{l}45 \\
\mathrm{Rh}\end{array}$ & $\begin{array}{l}46 \\
\mathrm{Pd}\end{array}$ & $\begin{array}{l}47 \\
\mathrm{Ag}\end{array}$ & $\begin{array}{l}48 \\
\mathrm{Cd}\end{array}$ & $\begin{array}{l}49 \\
\text { In }\end{array}$ & $\begin{array}{l}50 \\
\text { Sn }\end{array}$ & $\begin{array}{l}51 \\
\text { Sb }\end{array}$ & $\begin{array}{l}52 \\
\mathrm{Te}\end{array}$ & 5 \\
\hline & $\begin{array}{l}72 \\
\mathrm{Hf}\end{array}$ & $\begin{array}{l}73 \\
\text { Ta }\end{array}$ & $\begin{array}{l}74 \\
W\end{array}$ & $\begin{array}{l}75 \\
\operatorname{Re}\end{array}$ & $\begin{array}{l}76 \\
\text { Os }\end{array}$ & $\begin{array}{l}77 \\
\text { Ir }\end{array}$ & $\begin{array}{l}78 \\
\mathrm{Pt}\end{array}$ & $\begin{array}{l}79 \\
\mathrm{Au}\end{array}$ & $\begin{array}{l}80 \\
\mathrm{Hg}\end{array}$ & $\begin{array}{l}81 \\
\mathrm{TI}\end{array}$ & $\begin{array}{l}82 \\
\mathrm{~Pb}\end{array}$ & $\begin{array}{l}83 \\
\mathrm{Bi}\end{array}$ & $\begin{array}{l}84 \\
\text { Po }\end{array}$ & $\begin{array}{l}8 \\
A\end{array}$ \\
\hline & $(104)$ & $(105)$ & $(106)$ & $(107)$ & $(\overline{(108)}$ & $(109)$ & (IIO) & & & & & & & \\
\hline $\begin{array}{l}58 \\
\mathrm{Ce}\end{array}$ & $\begin{array}{l}59 \\
\mathrm{Pr}\end{array}$ & $\begin{array}{l}60 \\
\mathrm{Nd}\end{array}$ & $\begin{array}{l}61 \\
\mathrm{Pm}\end{array}$ & $\begin{array}{l}62 \\
\text { Sm }\end{array}$ & $\begin{array}{l}63 \\
\text { Eu }\end{array}$ & $\begin{array}{l}64 \\
\text { Gd }\end{array}$ & $\begin{array}{l}65 \\
T b\end{array}$ & $\begin{array}{l}66 \\
\text { Dy }\end{array}$ & $\begin{array}{l}67 \\
\text { Ho }\end{array}$ & $\begin{array}{l}68 \\
\text { Er }\end{array}$ & $\begin{array}{l}699 \\
\text { Tm }\end{array}$ & $\begin{array}{l}70 \\
\mathrm{Yb}\end{array}$ & $\begin{array}{l}71 \\
\mathrm{Lu}\end{array}$ & \\
\hline $\begin{array}{l}90 \\
\text { Th }\end{array}$ & $\begin{array}{l}91 \\
\mathrm{~Pa}\end{array}$ & $U^{92}$ & $\begin{array}{l}93 \\
\mathrm{~Np}\end{array}$ & $\begin{array}{l}94 \\
\mathrm{Pu}\end{array}$ & $\begin{array}{l}95 \\
\text { Am }\end{array}$ & $\begin{array}{l}96 \\
\mathrm{Cm}\end{array}$ & $\begin{array}{c}97 \\
\text { Bk }\end{array}$ & $\begin{array}{l}98 \\
\text { Cf }\end{array}$ & $\begin{array}{l}99 \\
E\end{array}$ & $\begin{array}{l}100 \\
\mathrm{Fm}\end{array}$ & $\begin{array}{l}101 \\
M v\end{array}$ & 102 & $(103)$ & \\
\hline
\end{tabular}




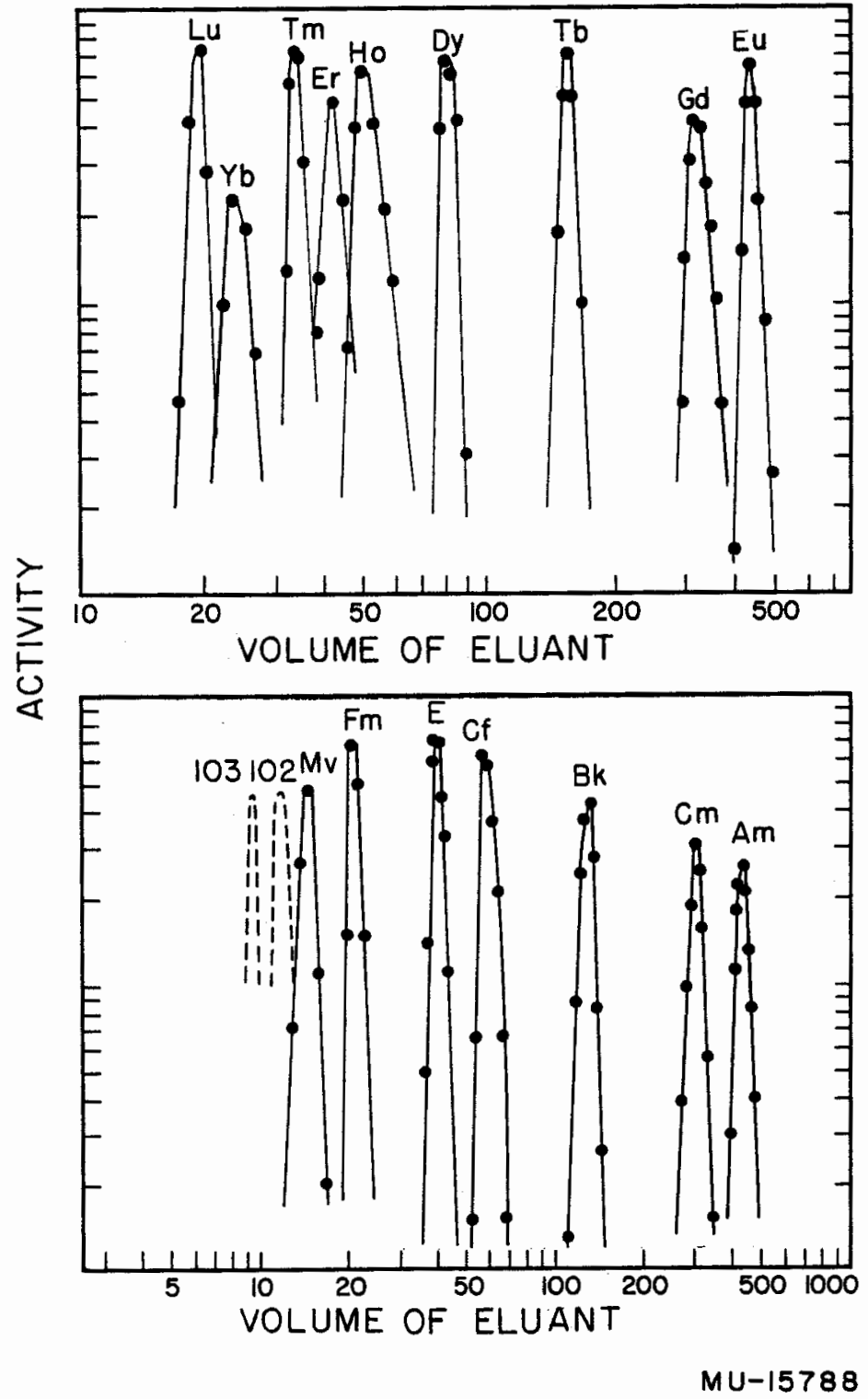

Slide 20 


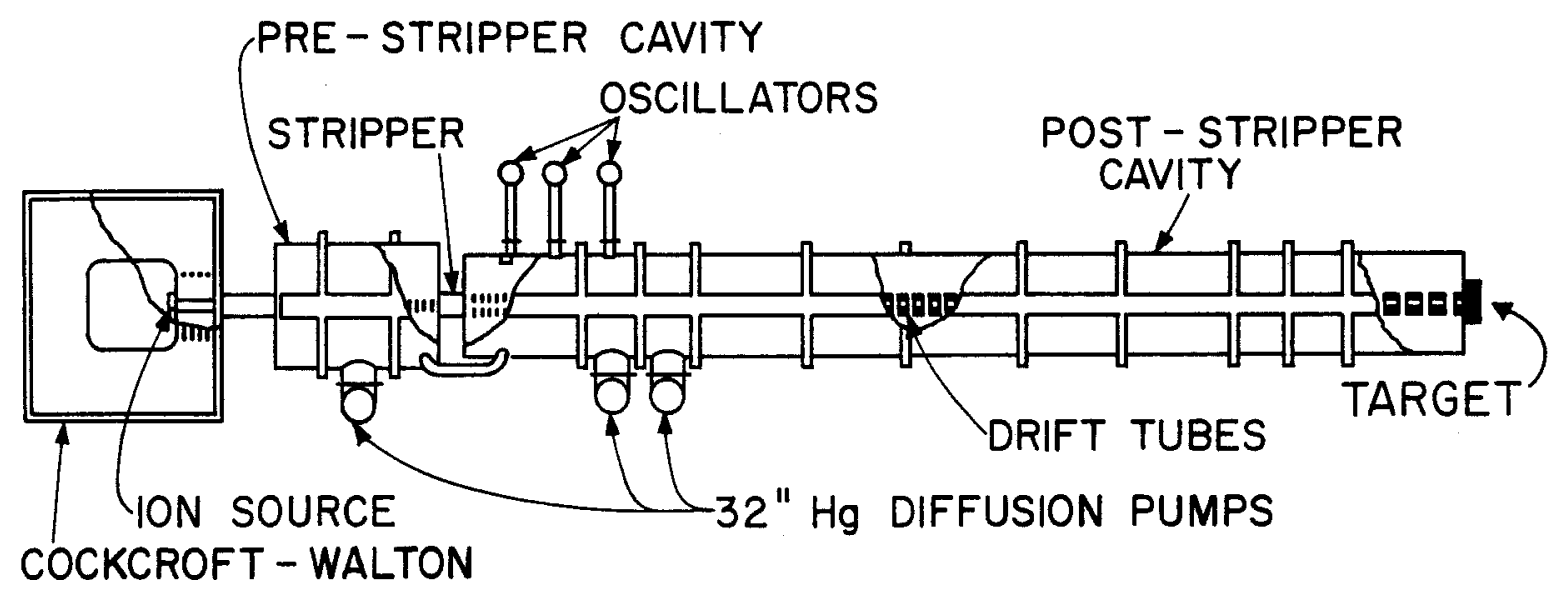




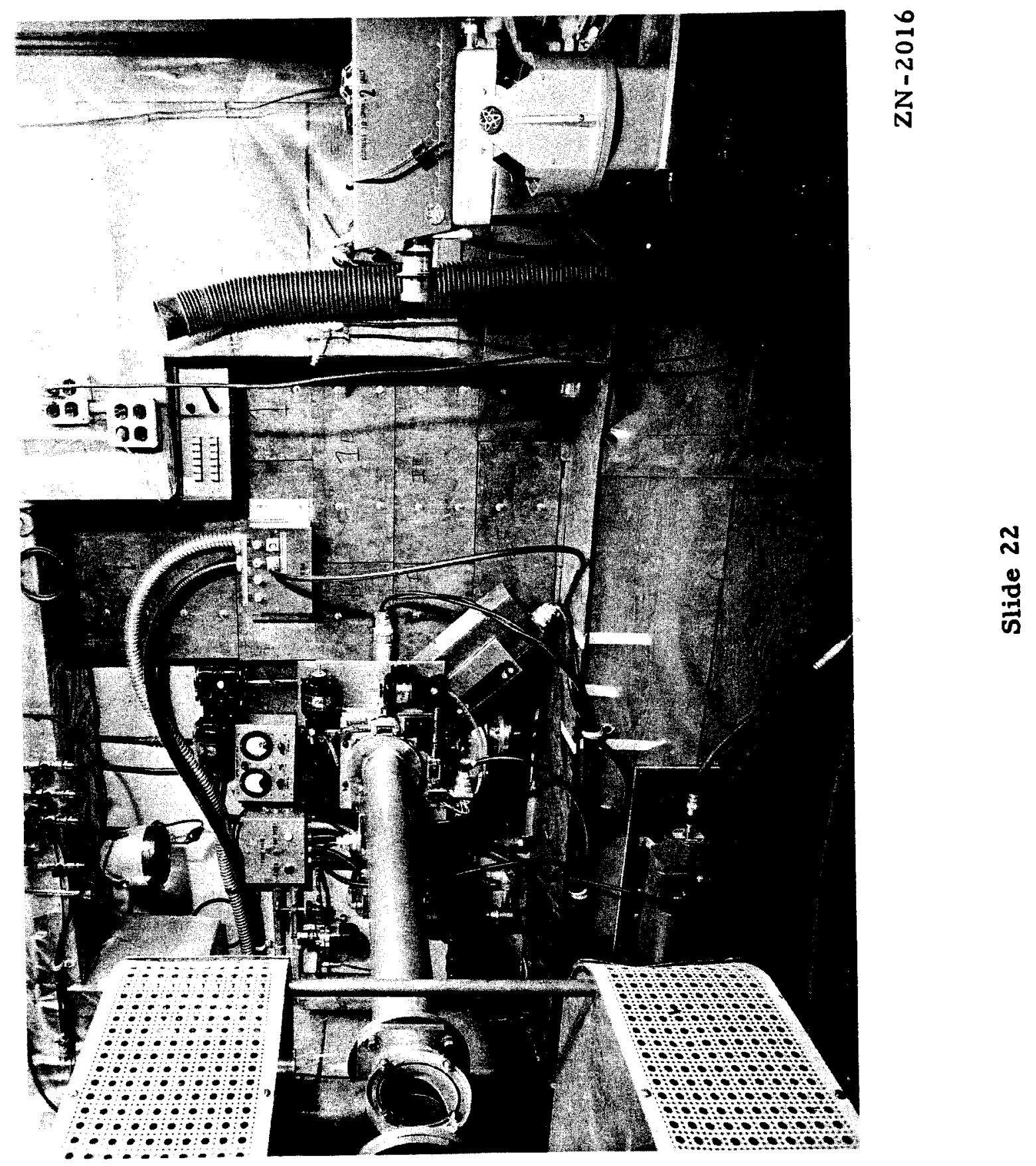




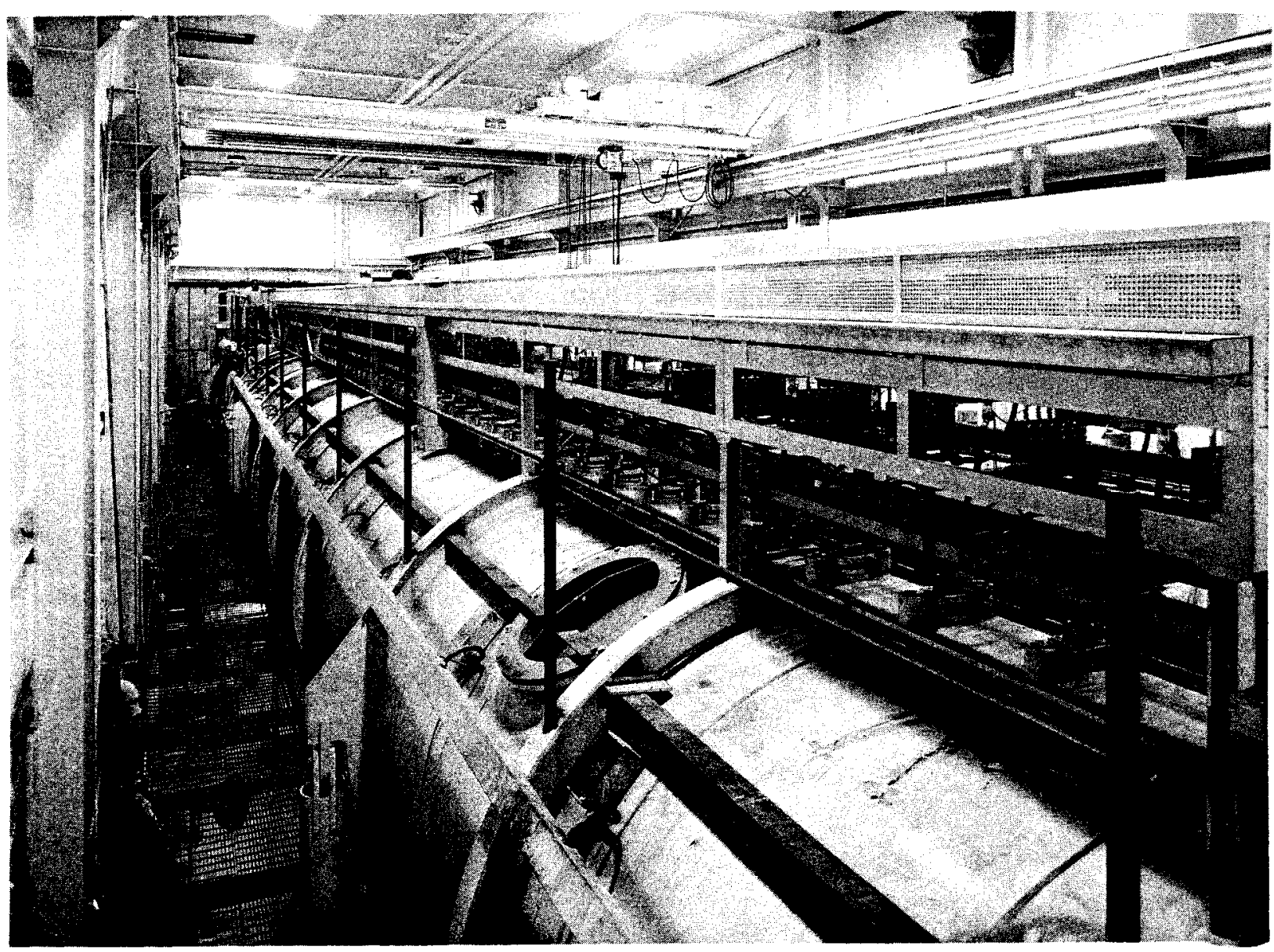

ZN-2015

Slide 23 


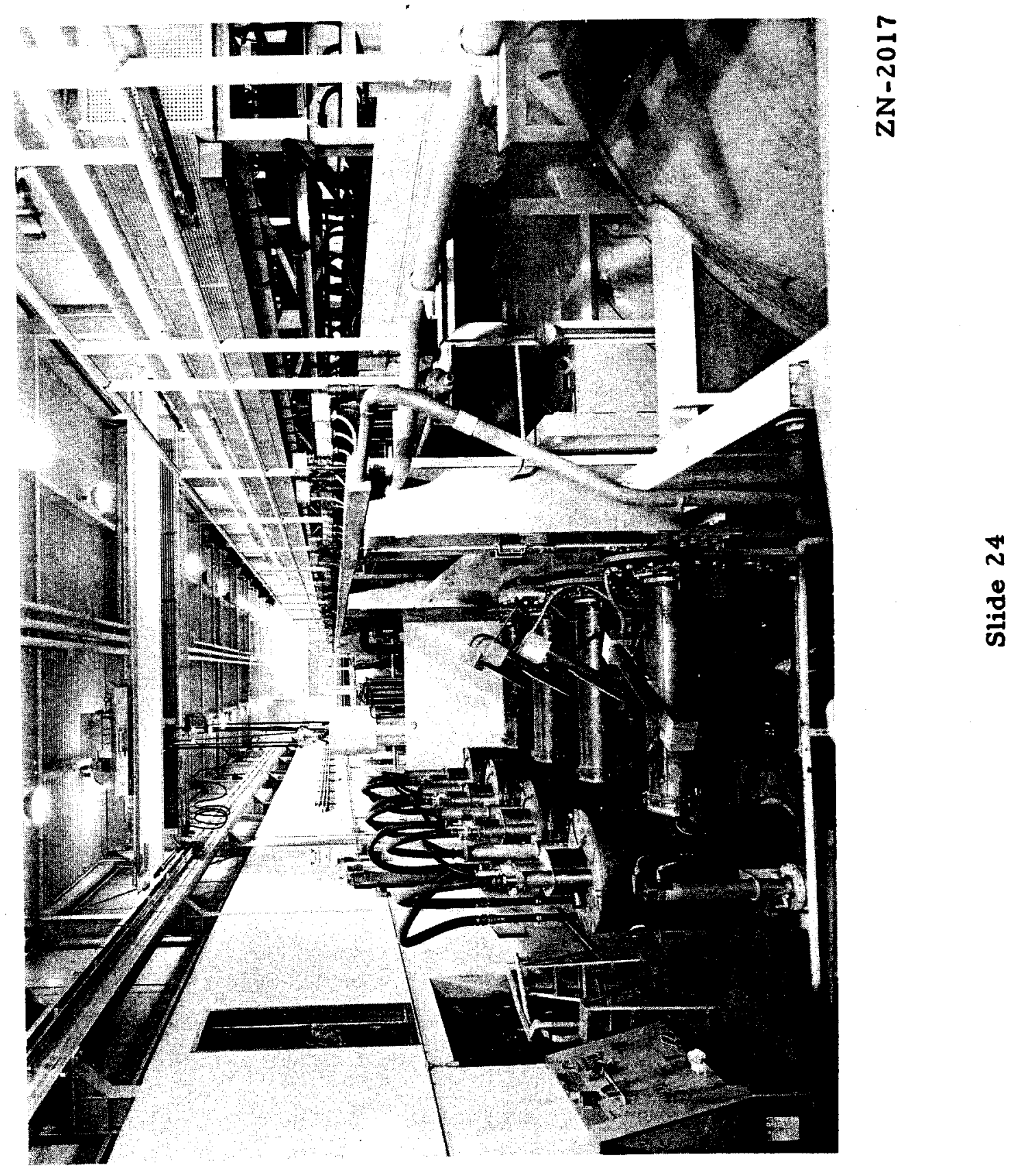




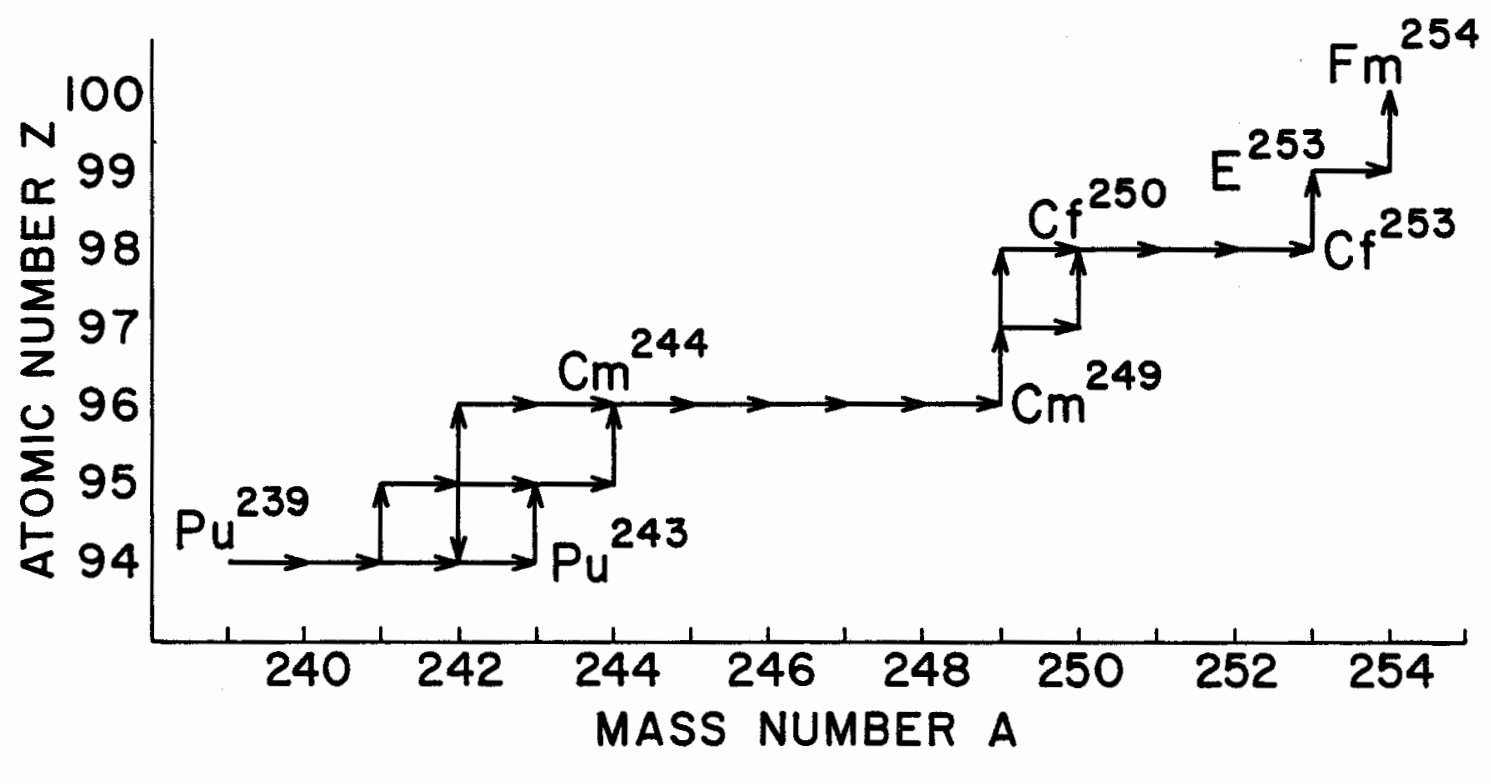

Slide 25 


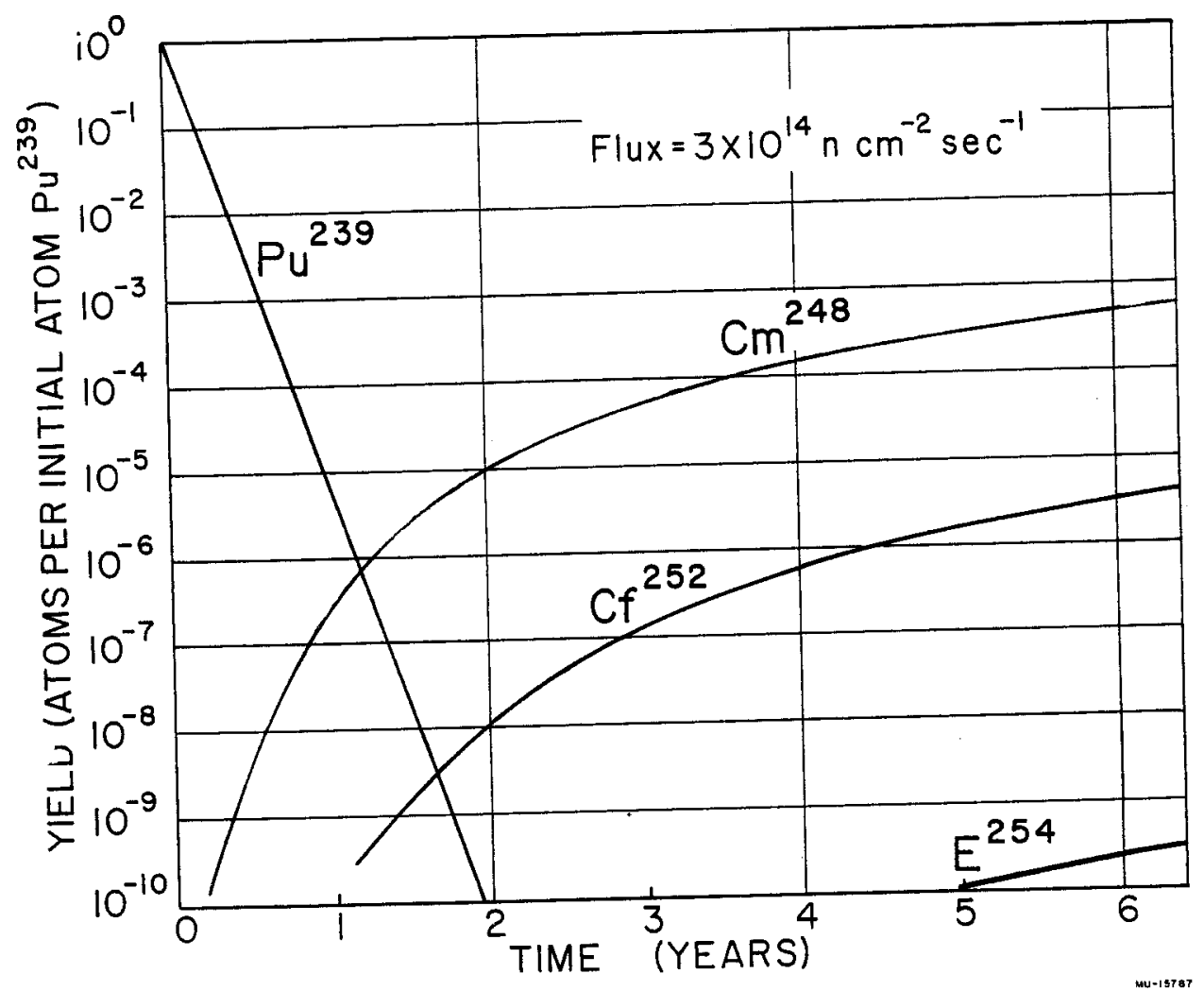

Slide 26 